\title{
Mechanism of the Northward-Propagating Intraseasonal Oscillation: Insights from a Zonally Symmetric Model*
}

\author{
Hae-Kyung Lee Drbohlav and Bin Wang \\ Department of Meteorology, School of Ocean and Earth Science and Technology, University of Hawaii at Manoa, Honolulu, Hawaii
}

(Manuscript received 9 July 2003, in final form 8 September 2004)

\begin{abstract}
The propagation and initiation mechanisms of the boreal summer intraseasonal oscillation (BSISO) in the south Asian summer monsoon are examined with a zonally symmetric atmospheric model. In the axially symmetric model the effects of zonally propagating atmospheric waves are intentionally excluded. The model specifies mean flows and depicts the lowest baroclinic mode and a barotropic mode in the free troposphere. The two vertical modes are coupled by the time-mean vertical wind shear. The model atmosphere produces a 15-20-day oscillation, which is characterized by northward propagation of convection from south of the equator to the Indian monsoon trough region and a reinitiation of convection in the region between $10^{\circ} \mathrm{S}$ and the equator.

The northward propagation in the model is produced by the free troposphere barotropic divergence, which leads convection by about a quarter of a cycle. The vertical advection of summer-mean easterly vertical wind shear by perturbation vertical motion inside the convective region induces barotropic divergence (convergence) to the north (south) of convection. This barotropic divergence triggers the moisture convergence in the boundary layer to the north of convection, causing the northward propagation of precipitation.

The development of convection in the Southern Hemisphere near the equator is also produced by the development of the barotropic divergence in the free troposphere. When the BSISO convection is located in the Indian monsoon trough region, it creates Hadley-type anomalous circulation. This Hadley-type circulation interacts with the monsoon flow through the meridional and vertical advections creating anomalous barotropic divergence and boundary layer convergence.
\end{abstract}

\section{Introduction}

Madden and Julian (1971) first discovered the 40-50day oscillation and characterized this oscillation as eastward-propagating, equatorially trapped, wavenumber-1 baroclinic anomalies [the Madden-Julian oscillation (MJO) mode hereafter]. Although this MJO mode is a yearlong characteristic of the climate record, it does not represent the complexity of the boreal summer intraseasonal oscillation (BSISO). During the boreal summer, not only eastward but also the meridional propagation of convection is found in the BSISO.

To characterize this complex structure of the MJO, Wang and Rui (1990) classified the MJO into three groups based on the direction of propagation. The first

\footnotetext{
* School of Ocean and Earth Science and Technology Publication Number 6489 and the International Pacific Research Center Publication Number 294.
}

Corresponding author address: Dr. Hae-Kyung Lee Drbohlav, Istituto Nazionale di Geofisica e Vulcanologia Via Donato Creti 12, 40128 Bologna, Italy.

E-mail: hael@bo.ingv.it group consists of equatorially trapped and eastwardpropagating convection. The second group includes the northeast or southeast movement of convection from the Maritime Continent to the western Pacific. The northeastward movement occurs during the Northern Hemisphere summer, whereas the southeastward propagation develops during the Southern Hemisphere summer.

The third group is characterized by eastward movement with a northward migration over the Indian and/ or the western Pacific Ocean from May to October. Observational studies have identified this northward movement of deep convection in the Indian Ocean and western North Pacific during the boreal summer (e.g., Yasunari 1979, 1980, 1981; Krishnamurti et al. 1985; Chen and Murakami 1988; Gadgil and Srinivasan 1990; Ouergli and De Felice 1996). In the Indian Ocean, convection originates near the equator and moves northward with a speed of about $0.75^{\circ}$ latitude day ${ }^{-1}$ (Krishnamurti and Subrahmanyam 1982).

Although this northward-propagating mode is less frequent in its occurrence $(20 \%)$ than the eastwardpropagating one $(65 \%)$, the accurate prediction of the northward-propagating mode is critical, since Indian monsoon variability can be affected by the northward- 
propagating convection (Yasunari 1979; Krishnamurti and Subrahmanyam 1982; Hartmann and Michelsen 1989; Gautier and Di Julio 1990). However, the predictability of the northward-propagating BSISO leaves room to be improved due to the lack of understanding of its mechanism.

A number of mechanisms have been proposed on two aspects of BSISO. The first aspect is the initiation of convection in the equatorial Indian Ocean. For example, Julian and Madden (1981) and Knutson et al. (1986) suggested that the initiation of equatorial outgoing longwave radiation (OLR) anomalies in the Indian monsoon region is associated with the eastwardpropagating equatorial OLR anomalies. According to $\mathrm{Hu}$ and Randall (1994, 1995), the initiation of convection near the equator in the Indian Ocean is a result of a stationary oscillating heat source that is forced by the nonlinear interaction among radiation, convection, and surface moisture flux. Wang and Xie (1997) attributed the initiation of the BSISO to westward-propagating off-equatorial moist Rossby waves. Their model results showed that when moist Rossby waves in both hemispheres propagate westward and stall over the Arabian Sea, the strong July-mean easterly vertical shear over the northern Indian Ocean traps the southern cell of the moist Rossby wave close to the equator. Consequently, the decay of the northern cell transfers energy to the southern cell and triggers development of convection over the equatorial Indian Ocean.

The second aspect of BSISO is the northward propagation of convection. Webster (1983) introduced the role of the land surface heat fluxes and hydrological cycle on the northward propagation of convection. Goswami and Shukla (1984) and Anderson and Stevens (1987) emphasized the interaction between convection and radiative relaxation in controlling the moist static stability. Wang and Xie (1997) used an intermediate model to show that the northward propagations over the Indian and western Pacific sectors are caused by emanation of the moist Rossby waves from Sumatra and the date line in equatorial western Pacific, respectively. The emanation occurs when the equatorial MJO mode (a coupled Kelvin-Rossby wave packet) attenuates over the Maritime Continent and in the central Pacific due to decreased moist static energy stored in the boundary layer. This northwestward emanation of Rossby waves were observed and documented (KemballCook and Wang 2001; Lawrence and Webster 2002). Especially, Lawrence and Webster (2002) argued that the impression of northward movement of convection at a given longitude is a result of eastward movement of the northwestward-oriented band of convection.

However, the relative importance of zonally propagating waves for the northward-propagating BSISO is still debatable. It is noticed that about one-half of the northward propagation that occurs over the Indian Ocean is independent of the equatorial eastwardpropagating MJO (Wang and Rui 1990). This suggests

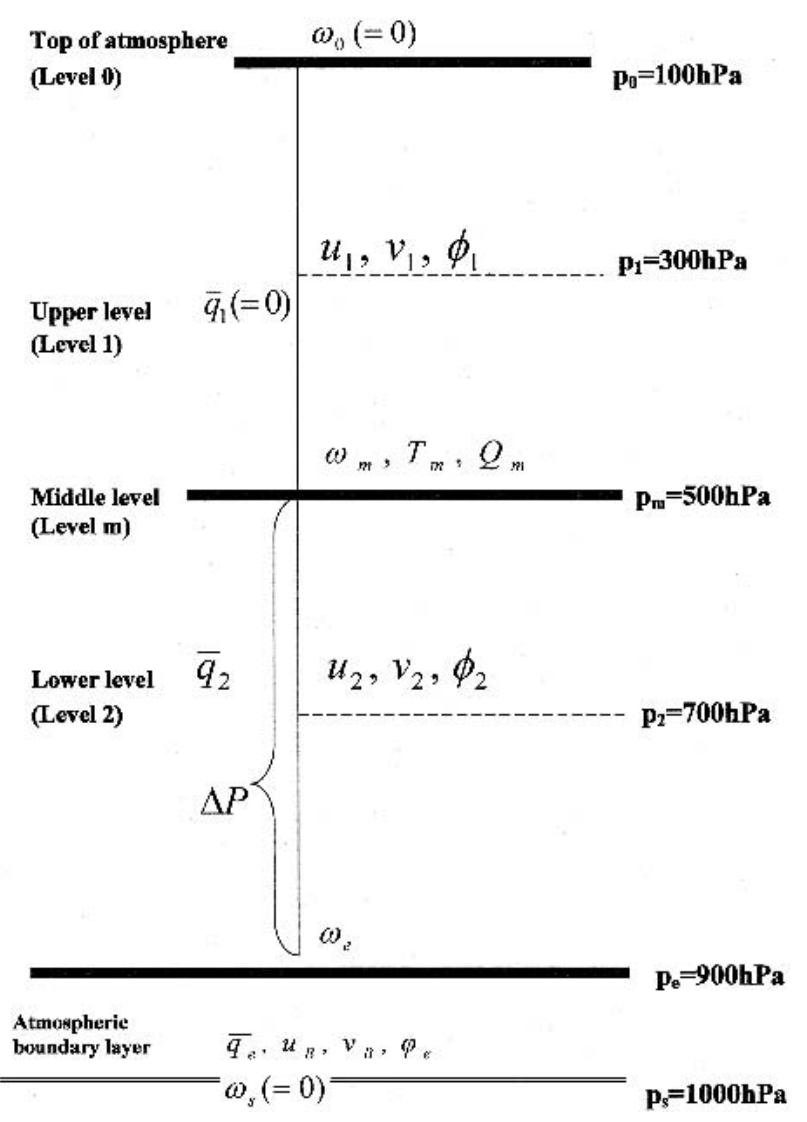

FIG. 1. Schematic diagram of the model.

that the northward propagation may not necessarily always tie up with equatorial wave dynamics. This study seeks to identify the independent mechanism that accounts for the northward-propagating BSISO in the Indian Ocean region. The uniqueness of this study lies in the assumption that the fundamental mechanism of the northward-propagating BSISO may exist without the zonally propagating wave effect. Based on this assumption, the research is directed to examine the atmospheric intrinsic dynamics regarding the initiation and propagation of the BSISO. In the next section, the model description is given. In section 3, the BSISO simulated in the zonally symmetric model is described. The proposed mechanism for the propagation (section 4) and initiation (section 5) of convection is followed by results from further experiments (section 6). Finally, the summary and discussion are given in section 7 .

\section{Zonally symmetric model}

In an attempt to exclude the influence of the zonally propagating atmospheric waves on the northward propagation of convection, a two-dimensional (2D) model is used. The $2 \mathrm{D}$ model is a zonally averaged version of the three-dimensional intermediate model developed by Wang and Xie (1997). The domain of the 

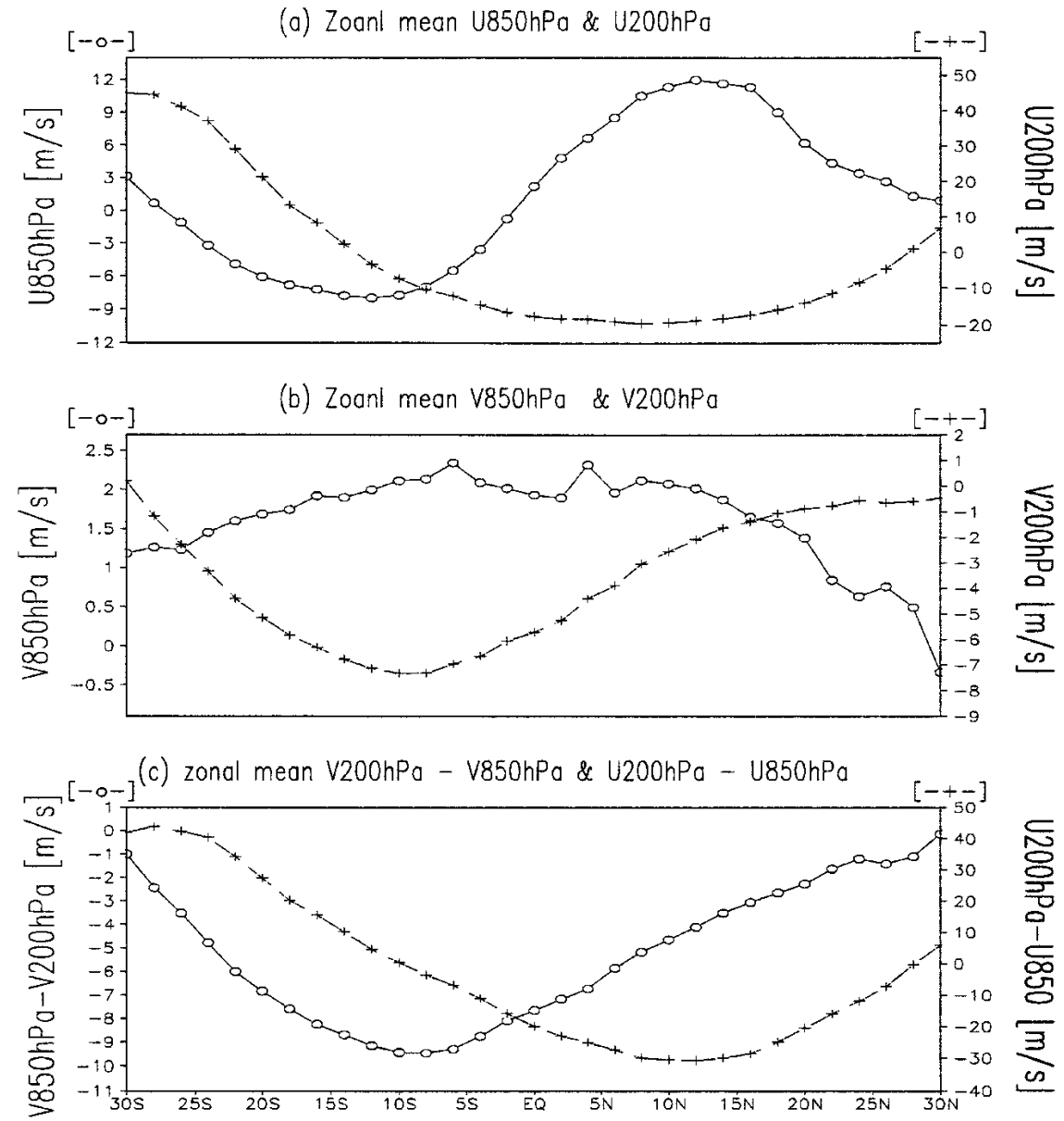

FIG. 2. Mean state used in the zonally averaged 2D model. (a) 850- and 200-hPa zonal winds, (b) $850-$ and $200-\mathrm{hPa}$ meridional winds, (c) vertical shear of zonal and meridional winds between 200 and $850 \mathrm{hPa}$, (d) average of vertical pressure velocity $(\bar{\omega})$ between 850 and 200 $\mathrm{hPa},(\mathrm{e})$ specific humidity, and (f) spatial variation of $850-\mathrm{hPa}$ winds (vector) and the average of the vertical pressure velocity between 850 and $200 \mathrm{hPa}$ (contour).

model is confined to an equatorial $\beta$ plane between $40^{\circ} \mathrm{S}$ and $40^{\circ} \mathrm{N}$ with a meridional resolution of $2^{\circ}$ latitude, and a time step of $10 \mathrm{~min}$. At the meridional boundaries the fluxes of mass, momentum, and heat normal to the boundaries vanish. The model solves the initial problem with the low-frequency perturbation motion (anomalies) and the steady-state basic flows of June-July-August-mean (JJA) state. The time integration is performed for the given initial condition of the Kelvin type; a cosine wave structure in the initial anomalous zonal winds in the absence of any initial anomalous meridional winds.

The model consists of a two-level free atmosphere and one well-mixed boundary layer. The subscripts 1 and 2 are used to indicate the upper $(300 \mathrm{hPa})$ and lower $(700 \mathrm{hPa})$ levels of the atmosphere, respectively. The subscript B represents the vertically averaged perturbation in the boundary layer, while the subscript e represents the perturbation at the top of the boundary layer (Fig. 1). Momentum and continuity equations are written at the upper and lower levels of free atmosphere (troposphere), and the thermodynamic and hydrostatic equations are written at the middle level (500 $\mathrm{hPa}$ ), which is denoted by the subscript $\mathrm{m}$. Using theses subscripts, the $2 \mathrm{D}$ perturbation primitive equations in a $P$-coordinate and equatorial $\beta$ plan are written as

$$
\begin{aligned}
\frac{\partial u_{1}^{\prime}}{\partial t}= & -\bar{v}_{1} \frac{\partial u_{1}^{\prime}}{\partial y}-v_{1}^{\prime} \frac{\partial \bar{u}_{1}}{\partial y}-\bar{\omega}_{m} \frac{u_{2}^{\prime}-u_{1}^{\prime}}{\Delta p} \\
& -\omega_{m}^{\prime} \frac{\bar{u}_{2}-\bar{u}_{1}}{\Delta p}+\beta y v_{1}^{\prime}-\varepsilon u_{1}^{\prime}+K \nabla^{2} u_{1}^{\prime}, \\
\frac{\partial v_{1}^{\prime}}{\partial t}= & -\bar{v}_{1} \frac{\partial v_{1}^{\prime}}{\partial y}-v_{1}^{\prime} \frac{\partial \bar{v}_{1}}{\partial y}-\bar{\omega}_{m} \frac{v_{2}^{\prime}-v_{1}^{\prime}}{\Delta p} \\
& -\omega_{m}^{\prime} \frac{\bar{v}_{2}-\bar{v}_{1}}{\Delta p}-\beta y u_{1}^{\prime}-\frac{\partial \phi_{1}^{\prime}}{\partial y}-\varepsilon v_{1}^{\prime} \\
& +K \nabla^{2} v_{1}^{\prime},
\end{aligned}
$$




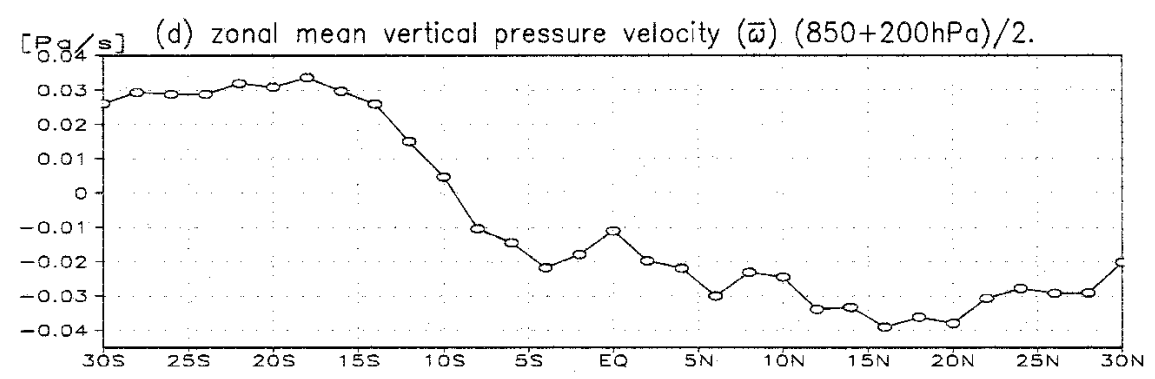

(e) zonal mean specific humidity

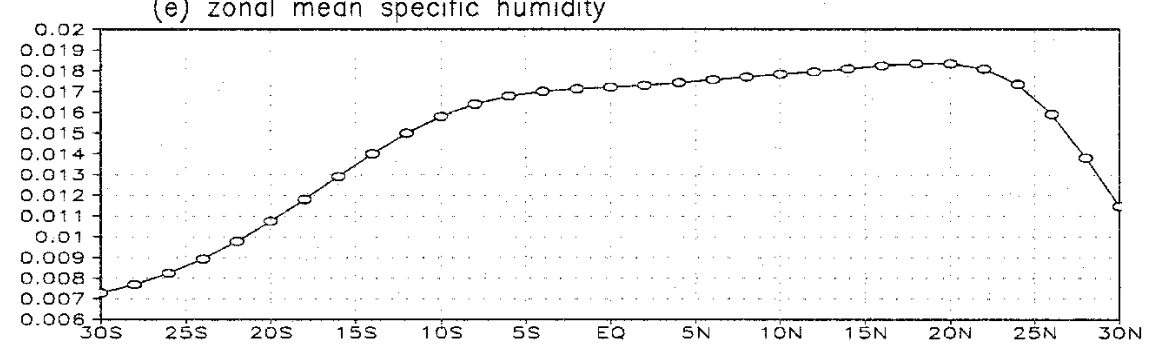

(f) $850 \mathrm{hPa}$ J.J.A. mean winds $[\mathrm{m} / \mathrm{s}]$ and $\bar{\omega}(850 \mathrm{hPa}+200 \mathrm{hPa}) / 2[\mathrm{~Pa} / \mathrm{s}]$

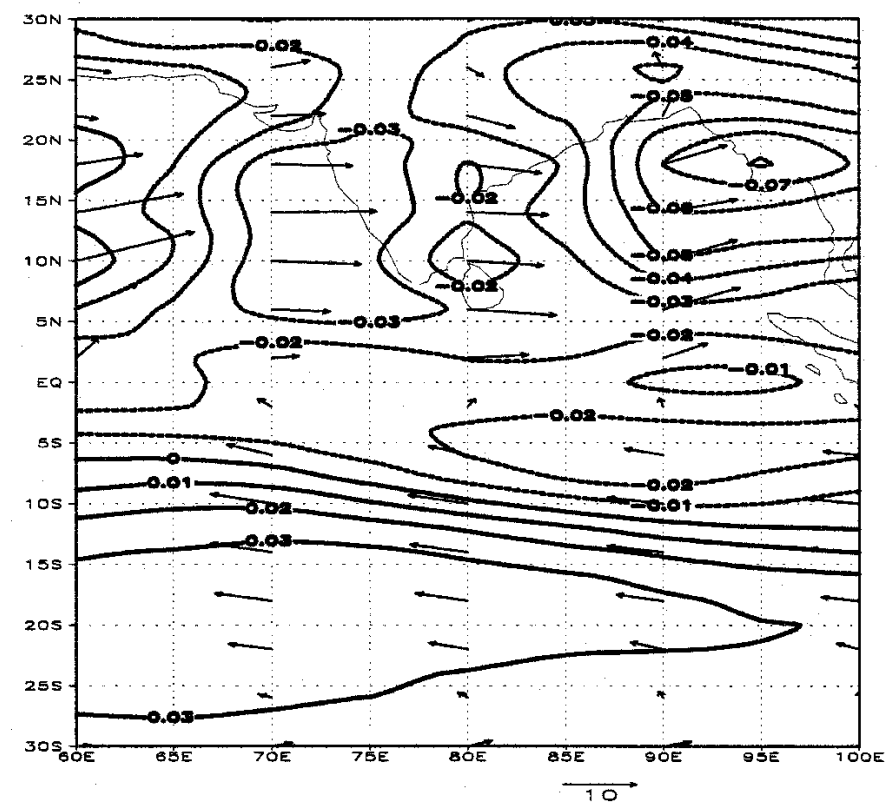

FIG. 2. (Continued)

$$
\begin{aligned}
\frac{\partial v_{1}^{\prime}}{\partial y}+\frac{\omega_{m}^{\prime}-0}{\Delta p}= & 0, \\
\frac{\partial u_{2}^{\prime}}{\partial t}= & -\bar{v}_{2} \frac{\partial u_{2}^{\prime}}{\partial y}-v_{2}^{\prime} \frac{\partial \bar{u}_{2}}{\partial y}-\bar{\omega}_{m} \frac{u_{2}^{\prime}-u_{1}^{\prime}}{\Delta p} \\
& -\omega_{m}^{\prime} \frac{\bar{u}_{2}-\bar{u}_{1}}{\Delta p}+\beta y v_{2}^{\prime}-\varepsilon u_{2}^{\prime}+K \nabla^{2} u_{2}^{\prime},
\end{aligned}
$$

$$
\begin{aligned}
\frac{\partial v_{2}^{\prime}}{\partial t}= & -\bar{v}_{2} \frac{\partial v_{2}^{\prime}}{\partial y}-v_{2}^{\prime} \frac{\partial \bar{v}_{2}}{\partial y}-\bar{\omega}_{m} \frac{v_{2}^{\prime}-v_{1}^{\prime}}{\Delta p} \\
& -\omega_{m}^{\prime} \frac{\bar{v}_{2}-\bar{v}_{1}}{\Delta p}-\beta y u_{2}^{\prime}-\frac{\partial \phi_{2}^{\prime}}{\partial y}-\varepsilon v_{2}^{\prime} \\
& +K \nabla^{2} v_{2}^{\prime}, \\
\frac{\partial v_{2}^{\prime}}{\partial y}+ & \frac{\omega_{e}^{\prime}-\omega_{m}^{\prime}}{\Delta p}=0,
\end{aligned}
$$



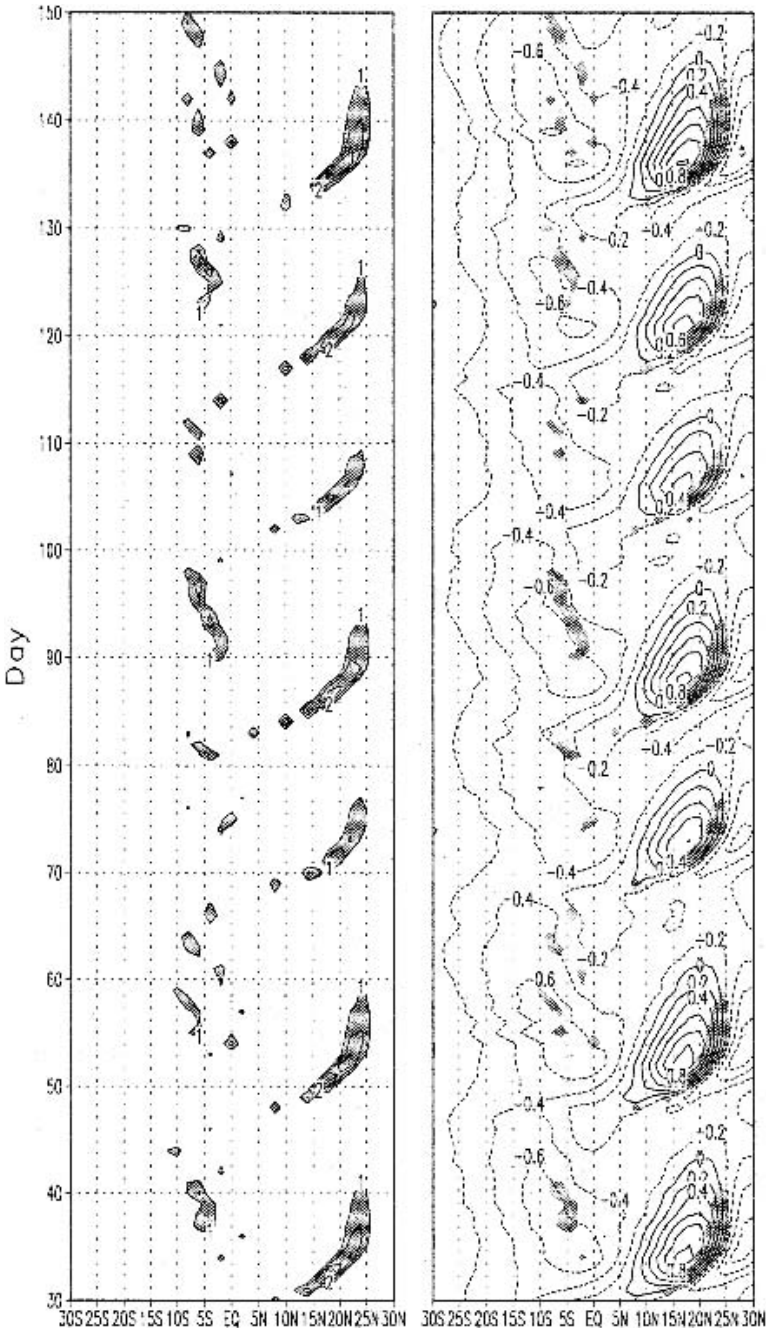

(a) Pr. rate $[\mathrm{mm} / \mathrm{doy}]$

(b) $u^{1700 h P o}[\mathrm{~m} / \mathrm{s}]$

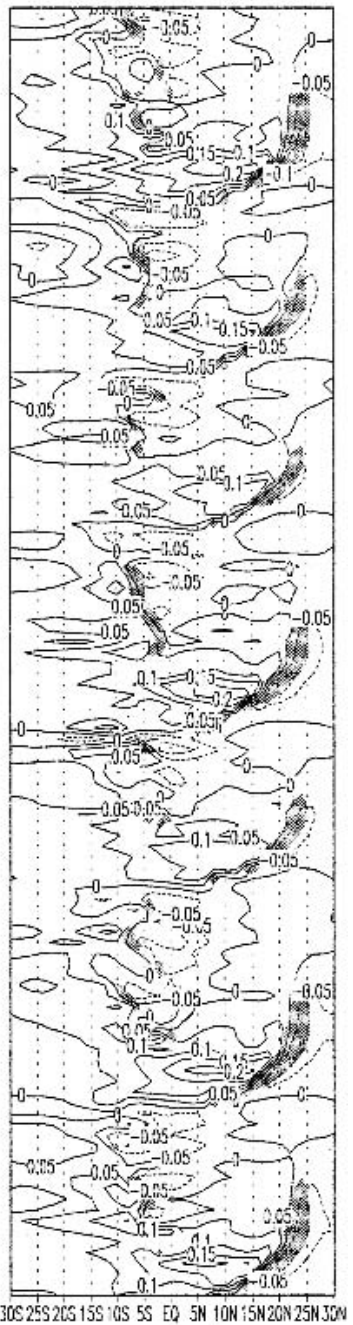

(c) $1700 \mathrm{hPo}[\mathrm{m} / \mathrm{s}]$

FIG. 3. Latitude-time section of anomalies from the zonally averaged 2D model. (a) The Pr $\left(\mathrm{mm} \mathrm{day}^{-1}\right),(\mathrm{b})$ low-level zonal wind $\left(\mathrm{m} \mathrm{s}^{-1}\right)$, and (c) low-level meridional wind $\left(\mathrm{m} \mathrm{s}^{-1}\right)$. Shading indicates precipitation greater than $1 \mathrm{~mm}$ day $^{-1}$.

$$
\begin{aligned}
\frac{\partial T_{m}^{\prime}}{\partial t}= & -\left(\frac{\bar{v}_{1}+\bar{v}_{2}}{2}\right) \frac{\partial T_{m}^{\prime}}{\partial y}-\left(\frac{v_{1}^{\prime}+v_{2}^{\prime}}{2}\right) \frac{\partial \bar{T}_{m}}{\partial y} \\
& +\frac{p_{m}}{R} \bar{S} \omega_{m}^{\prime}+\frac{Q_{m}^{\prime}}{C_{p}}-\mu T_{m}^{\prime}+K \nabla^{2} T_{m}^{\prime}, \\
\frac{\phi_{2}^{\prime}-\phi_{1}^{\prime}}{\Delta p}= & -\frac{R T_{m}^{\prime}}{p_{m}},
\end{aligned}
$$

where overbars and primes represent basic-state and perturbation quantity; $u, v, \omega, \phi$, and $T$ denote zonal and meridional winds, vertical pressure velocity, geopotential, and temperature, respectively; $\varepsilon, \mu$, and $R$ are the Rayleigh friction coefficient, Newtonian cooling coefficient, and specific gas constant, respectively; $K$ is the turbulent horizontal momentum or thermal diffusion coefficient; $\mathrm{S}$ is the dry static stability parameter; and $\triangle p$ is the half-depth of the free troposphere.

The governing equations in the steady, well-mixed boundary layer can be described as

$$
\begin{aligned}
\beta y v_{B}^{\prime}-E_{x} u_{B}^{\prime} & =0, \\
-\beta y u_{B}^{\prime}-\frac{\partial \phi_{e}^{\prime}}{\partial y}-E_{y} v_{B}^{\prime} & =0, \\
\omega_{e}^{\prime} & =\left(p_{s}-p_{e}\right)\left(\frac{\partial v_{B}^{\prime}}{\partial y}\right),
\end{aligned}
$$

where $p_{s}$ and $p_{e}$ are pressure at the model surface and at the top of boundary layer, respectively; $\phi_{e}^{\prime}$ denotes 

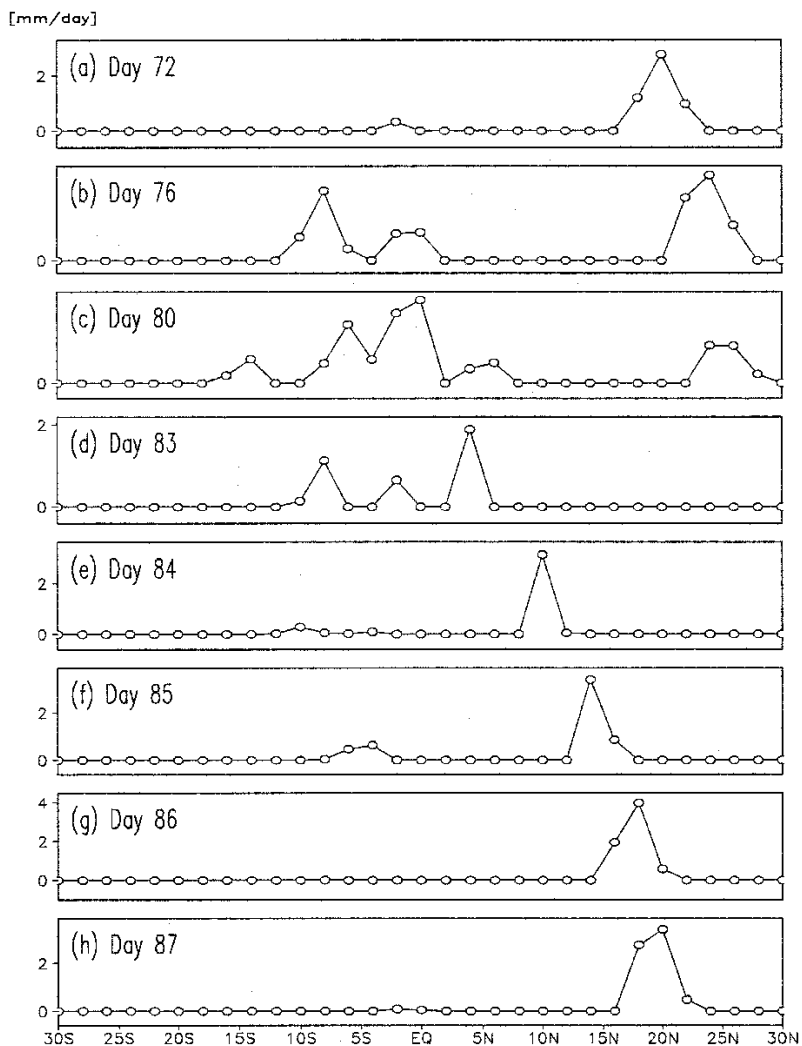

FIG. 4. Latitudinal variation of precipitation rate $\left(\mathrm{mm} \mathrm{day}^{-1}\right)$ on days (a) 72, (b) 76, (c) 80, (d) 83, (e) 84, (f) 85, (g) 86, and (h) 87 .

perturbation geopotential at $p_{e} ; u_{B}^{\prime}$ and $v_{B}^{\prime}$ are vertically averaged perturbation zonal and meridional winds in the boundary layer, respectively; and $E_{x}$ and $E_{y}$ are Rayleigh friction coefficients in the zonal and meridional directions, respectively. From (2), the Ekman pumping velocity can be written as

$$
\omega_{e}^{\prime}=D_{3} \frac{\partial^{2} \phi_{e}^{\prime}}{\partial y^{2}}+D_{4} \frac{\partial \phi_{e}^{\prime}}{\partial y}
$$

where the coefficients are

$$
\begin{aligned}
& D_{3}=-\frac{\left(p_{s}-p_{e}\right) E_{x}}{E_{x} E_{y}+\beta^{2} y^{2}}, \\
& D_{4}=\frac{2\left(p_{s}-p_{e}\right) E_{x} \beta^{2} y}{\left(E_{x} E_{y}+\beta^{2} y^{2}\right)^{2}} .
\end{aligned}
$$

Due to mass conservation in a vertical column, the Ekman pumping velocity in the barotropic boundary layer is related to free tropospheric divergence as the following:

$$
\omega_{e}^{\prime}=-\Delta p \sum_{k=1}^{2} \frac{\partial v_{k}^{\prime}}{\partial y}
$$

Baroclinic $\partial\left(\partial v^{\prime} / \partial y\right) / \partial t *\left(\bar{q}_{2}\right)$ and prec. rate

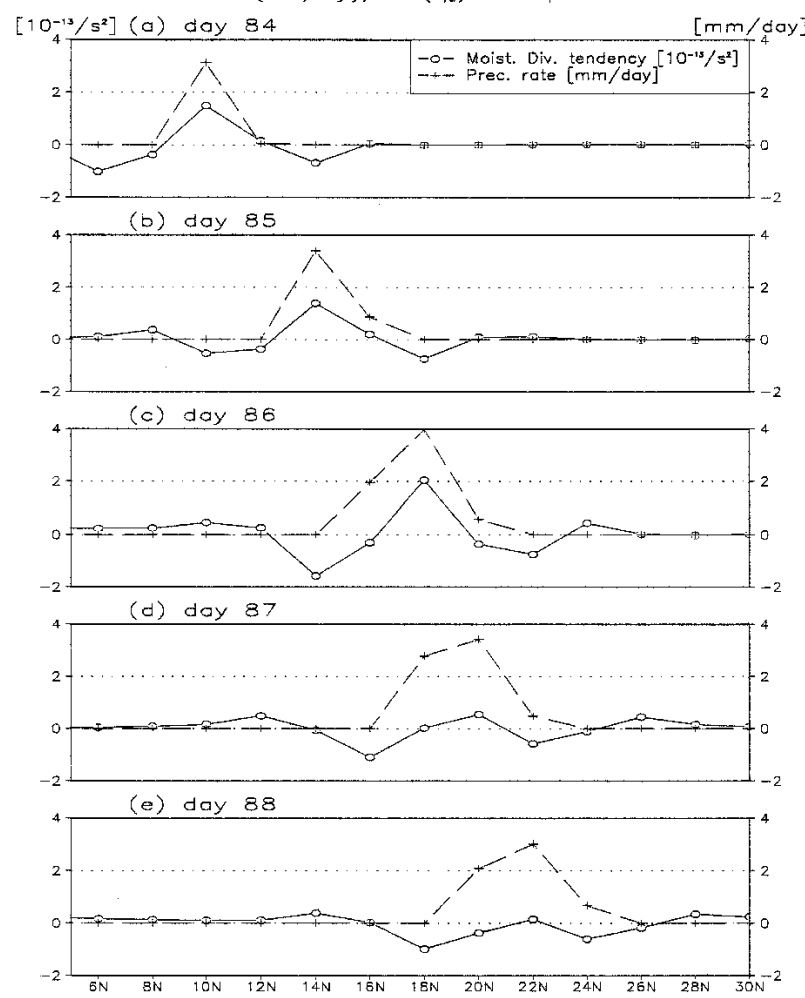

FIG. 5. Latitudinal variation of precipitation rate (-+-) and baroclinic mode of moisture-divergence tendency $\left[\partial / \partial t\left(\partial v^{\prime}-/ \partial y\right) \bar{q}_{2}\right.$, -o-] on days (a) 84, (b) 85, (c) 86, (d) 87, and (e) 88 .

Combining (3) and (4) leads to an elliptical equation for $\phi_{e}^{\prime}$ :

$$
D_{3} \frac{\partial^{2} \phi_{e}^{\prime}}{\partial y^{2}}+D_{4} \frac{\partial \phi_{e}^{\prime}}{\partial y}=-\Delta p \sum_{k=1}^{2}\left(\frac{\partial v_{K}^{\prime}}{\partial y}\right) .
$$

Here, the assumption, $\phi_{e}^{\prime}=\phi_{2}^{\prime}$ is made in order to close the governing equations.

In the model, precipitation rate $(\mathrm{Pr})$ is determined by the moisture convergence in the planetary boundary layer, and in the lower layer of the free atmosphere

$$
\operatorname{Pr}=-\left(p_{s}-p_{e}\right)\left(\frac{\partial v_{B}^{\prime}}{\partial y}\right) \bar{q}_{e}-\Delta p\left(\frac{\partial v_{2}^{\prime}}{\partial y}\right) \bar{q}_{2},
$$

where $\bar{q}_{\mathrm{e}}$ and $\bar{q}_{2}$ are specific humidity of JJA-mean climatology. Combining (2c) and (4) leads to

$$
\Delta p\left(\frac{\partial v_{1}^{\prime}}{\partial y}+\frac{\partial v_{2}^{\prime}}{\partial y}\right)=-\left(p_{s}-p_{e}\right)\left(\frac{\partial v_{B}^{\prime}}{\partial y}\right),
$$

which shows that the divergence in the free atmosphere (upper and lower troposphere) is balanced by the convergence in the boundary layer. Substituting (7) into (6) gives

$$
\operatorname{Pr}=\Delta p\left(\frac{\partial v_{1}^{\prime}}{\partial y}+\frac{\partial v_{2}^{\prime}}{\partial y}\right) \bar{q}_{e}-\Delta p\left(\frac{\partial v_{2}^{\prime}}{\partial y}\right) \bar{q}_{2} .
$$


Barotropic $\partial\left(\partial v^{\prime} / \partial y\right) / \partial t *\left(2 \bar{q}_{0}-\bar{q}_{2}\right)$ and prec. rate

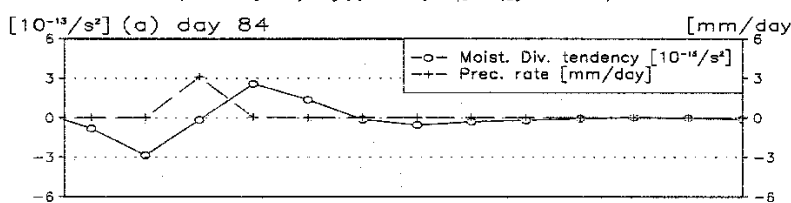

(b) day 85

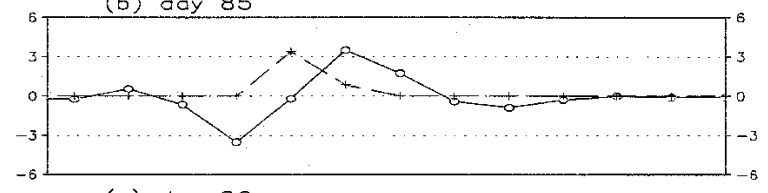

(c) day 86

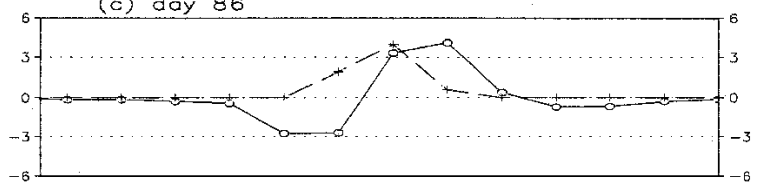

(d) doy 87

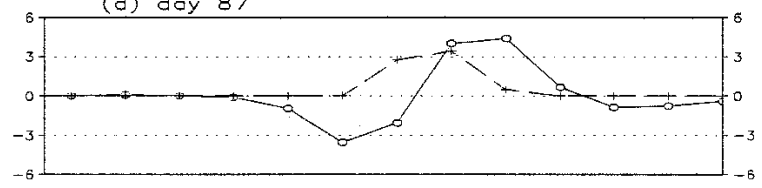

(e) day 88

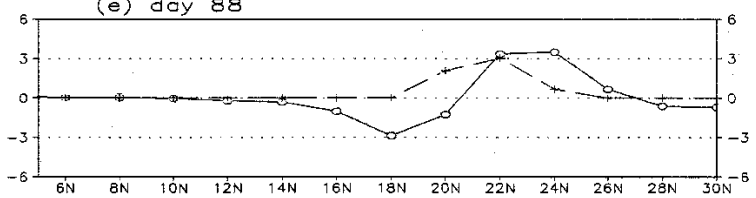

FIG. 6. Latitudinal variation of precipitation rate (-+-) and barotropic mode of moisture-divergence tendency $\left[\partial / \partial t\left(\partial v^{\prime+} /\right.\right.$ дy) $\left.\left(2 \bar{q}_{e}-\bar{q}_{2}\right),-\circ-\right]$ on days (a) 84, (b) 85, (c) 86, (d) 87, and (e) 88 .

From (1.1c), (1.2c), and (8), the Pr and the condensational heating $\left(Q_{m}^{\prime}\right)$ at the middle atmosphere $\mathrm{p}_{\mathrm{m}}$ are expressed as

$$
\begin{aligned}
\operatorname{Pr} & =-\omega_{e}^{\prime}\left(\bar{q}_{2}-\bar{q}_{e}\right)-\omega_{m}^{\prime} \bar{q}_{2}, \\
Q_{m}^{\prime} & =\frac{\delta b L_{c}}{\Delta p}\left[-\omega_{m}^{\prime} \bar{q}_{2}-\omega_{e}^{\prime}\left(\bar{q}_{e}-\bar{q}_{2}\right)\right],
\end{aligned}
$$

where $Q_{m}^{\prime}$ represents the irreversible condensational heating; $b$ measures the ratio of the amount of water vapor that condenses out to the total moisture convergence in the same air column; $\mathrm{L}_{\mathrm{c}}$ is the latent heat; the switch-on parameter, $\delta$ is 1 when the $\operatorname{Pr}$ in (9a) is positive and 0 otherwise.

\section{Simulated BSISO}

\section{a. Basic state}

The 2D model basic state represents an area average from $60^{\circ}$ to $100^{\circ} \mathrm{E}$ corresponding roughly to the south Asian summer monsoon region. The zonally averaged time-mean flow is a JJA-mean circulation, which is cal-
Barotropic $\partial\left(-\beta y w^{\prime}\right) / \partial y *\left(2 \bar{c}_{1}-\bar{q}_{2}\right)$ and prec. rate

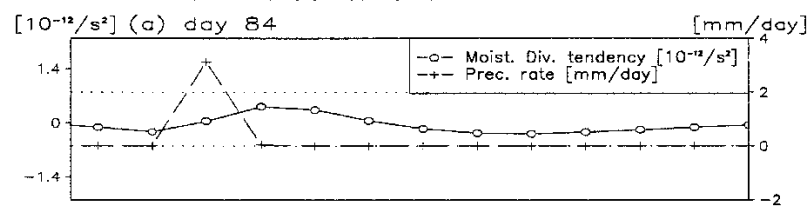

(b) day 85

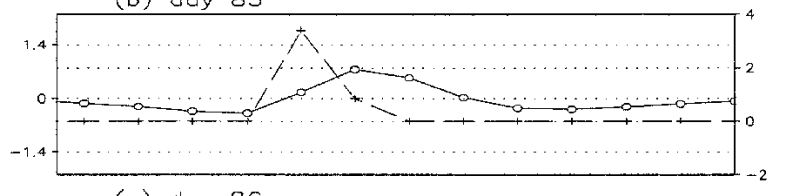

(c) day 86

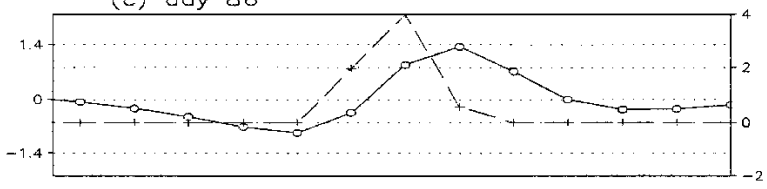

(d) day 87

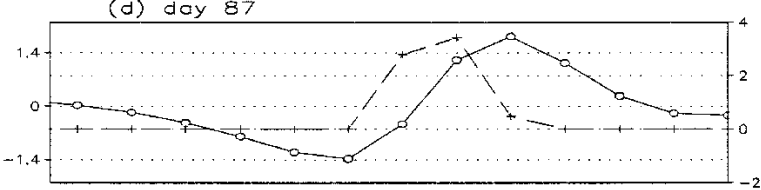

(e) day 88

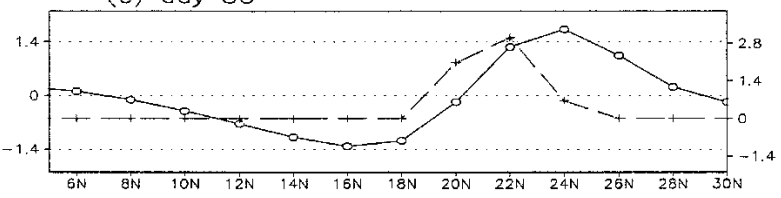

FIG. 7. Latitudinal variation of precipitation rate (-+-) and barotropic mode of moisture-divergence tendency induced by the Coriolis force $\left[\partial / \partial y\left(-\beta y u^{\prime+}\right)\left(2 \bar{q}_{e}-\bar{q}_{2}\right),-\circ-\right]$ on days (a) 84 , (b) 85, (c) 86, (d) 87 , and (e) 88 .

culated from the European Centre for Medium-Range Weather Forecasts (ECMWF) grid analysis data for the period 1979-92. The 200- and 850-hPa winds are used as the mean winds at the upper and lower levels of the model. The mean temperature at the middle level is determined from geopotential thickness between 200 and $850 \mathrm{hPa}$ by assuming hydrostatic balance. The vertical pressure velocity at the middle level is obtained by averaging the values at 200 and $850 \mathrm{hPa}$. The specific humidity at $1000 \mathrm{hPa}$ is used for the basic-state free atmospheric moisture content. A complete description of the moisture profile can be found in Wang (1988).

Figure 2 illustrates the meridional structure of the basic state. The maximum low-level easterlies and westerlies are found at $12^{\circ} \mathrm{S}$ and $12^{\circ} \mathrm{N}$, respectively (Fig. 2a). In the upper troposphere, zonal winds become westerlies to the south of $14^{\circ} \mathrm{S}$, while easterlies are dominant elsewhere (Fig. 2a). The vertical shear of zonal winds becomes zero at $10^{\circ} \mathrm{S}$, and westerly wind shear (easterly wind shear) is found in the area south (north) of $10^{\circ} \mathrm{S}$ (Fig. 2c). The JJA-mean meridional winds in the lower atmosphere are southerlies except in the region north of $28^{\circ} \mathrm{N}$ (Fig. 2b). In the upper atmosphere, northerlies are persistent in the whole domain (Fig. 2b). The ver- 


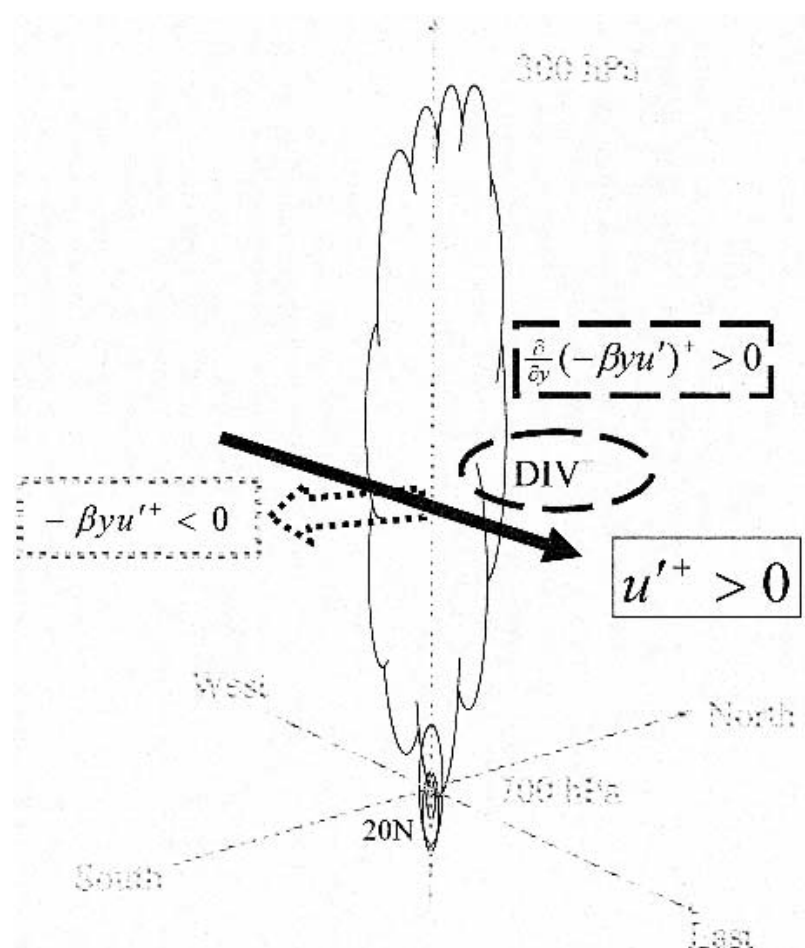

FIG. 8. Schematic diagram of mechanism for the northward propagation of convection at $20^{\circ} \mathrm{N}$. The barotropic mode is denoted by superscript + . The solid arrow denotes the barotropic mode of anomalous zonal winds. The dotted arrow denotes the barotropic mode of the Coriolis force. The dashed circle implies the increase of the barotropic divergence [i.e., $\partial / \partial y\left(-\beta y u^{\prime+}\right)>0$ ] to the north of $20^{\circ} \mathrm{N}$

tical shear in the meridional winds is northerly shear, which means that the northerly wind increases with increasing height (Fig. 2c).

The JJA-mean vertical pressure velocity in the tropical region indicates that a sinking (rising) motion is dominant to the south (north) of $10^{\circ} \mathrm{S}$ (Fig. 2d). The JJA-mean specific humidity (Fig. 2e) increases from southern boundary toward the Northern Hemisphere. A relatively sharp decrease of specific humidity is found north of $20^{\circ} \mathrm{N}$, since the existence of land decreases the specific humidity. The spatial variation of low-level JJA-mean winds and the JJA-mean vertical pressure velocity is shown in Fig. 2f. Note that within the domain of this study $\left(60^{\circ}-100^{\circ} \mathrm{E}\right)$, the zonal variation of JJA-mean atmospheric variables is much smaller than the meridional variation. Thus, the zonally averaged basic state adequately represents the spatial variation in this domain.

\section{b. Simulation of intraseasonal oscillation in the zonally averaged model}

Figure 3 shows the evolution of precipitation, and the low-level zonal and meridional winds simulated by the 2D model. Northward propagation of precipitation is

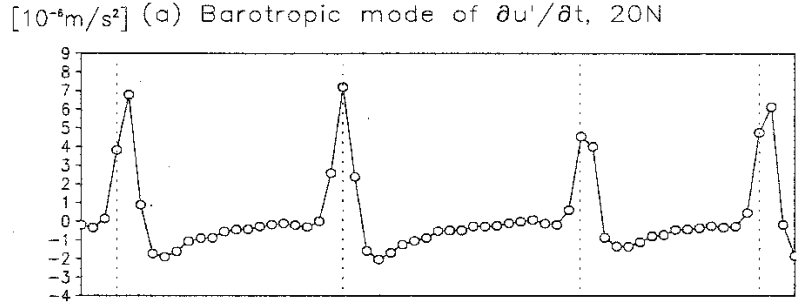

(b) Barotropic mode of $-\omega^{\prime} *(\partial \bar{u} / \partial p)$

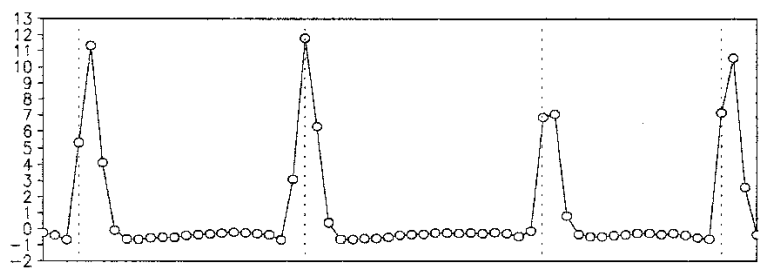

(c) Barotropic mode of the other components

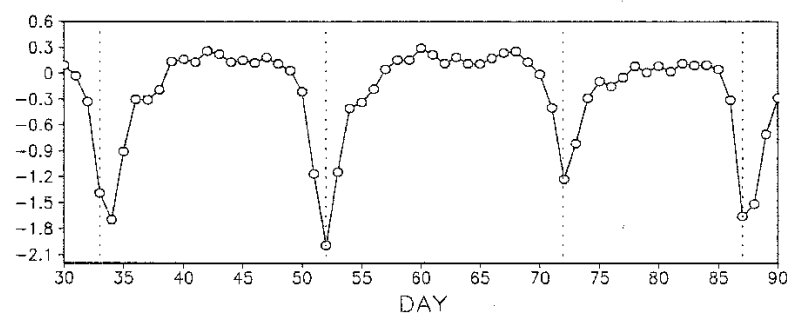

FIG. 9. Time series of barotropic mode of momentum equation for zonal wind anomaly at $20^{\circ} \mathrm{N}$ : (a) $\partial u^{\prime} / \partial t^{+}$, (b) $\left(-\omega^{\prime} \partial \bar{u} / \partial p\right)^{+}$, and (c) sum of $\left(-v^{\prime} \partial \bar{u} / \partial y\right)^{+},\left(-\bar{v} \partial u^{\prime} / \partial p\right)^{+},\left(-\bar{\omega} \partial u^{\prime} / \partial p\right)^{+}$, and $\beta y v^{\prime+}$. The vertical dotted line indicates days when precipitation in $20^{\circ} \mathrm{N}$ reaches the maximum.

evident with a period of about 15-20 days (Fig. 3a). Two locations of strong precipitation are found. One covers from $10^{\circ}$ to $25^{\circ} \mathrm{N}$, and the other is located between $10^{\circ} \mathrm{S}$ and the equator. Although a weak southward propagation of precipitation from $2^{\circ}$ to $10^{\circ} \mathrm{S}$ is found, the southern area of precipitation is not as well organized as its counterpart in the north. The lowlevel winds in Figs. $3 \mathrm{~b}$ and $3 \mathrm{c}$ show that convection (precipitation) is followed by westerlies and southerlies. While the period of the oscillation is somewhat shorter than observed, the simulated northward propagation has a realistic structure (e.g., Sikka and Gadil 1980; Lawrence and Webster 2002). The ability of the zonally averaged model in simulating BSISO suggests that the zonally propagating Rossby wave-like or Kelvin wave-like convection is not a critical element for the northward propagation and the initiation of convection.

For a more detailed analysis, the period between days 72 and 87 is chosen as a life cycle of BSISO (Fig. 4). At day 72 , the maximum precipitation is located at the latitude $20^{\circ} \mathrm{N}$. When this precipitation anomaly moves northward from day 72 to 80 , its intensity decreases from more than $2.8 \mathrm{~mm} \mathrm{day}^{-1}$ (day 72) to less than $0.25 \mathrm{~mm} \mathrm{day}^{-1}$ (day 80). Meanwhile, new convec- 
$\left[10^{-1} \mathrm{~m} / \mathrm{s}^{2}\right]$ (a) Borotropic mode of $\partial u^{\prime} / \partial t, 4 S$

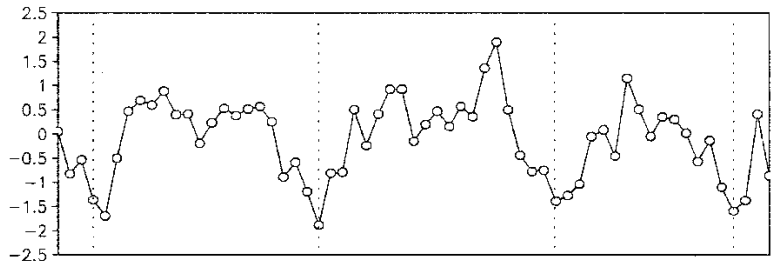

(b) Barotropic mode of $-v^{\prime} *(\partial \bar{u} / \partial y)-\bar{\omega} *\left(\partial u^{\prime} / \partial p\right)$

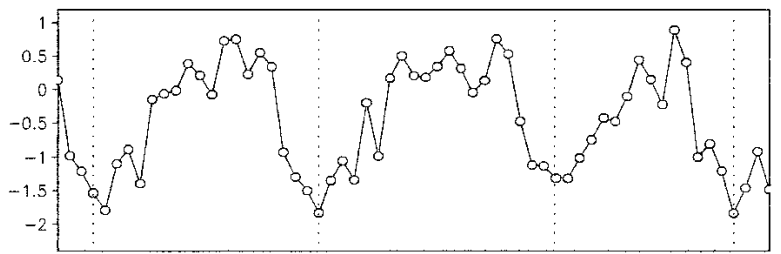

(c) Barotropic mode of the other components

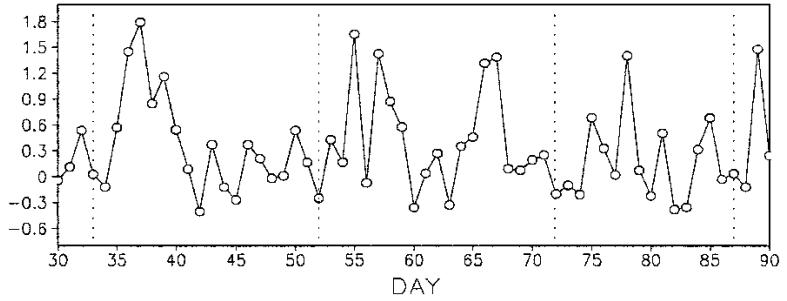

FIG. 10. Time series of barotropic mode of momentum equation for zonal wind anomaly at $4^{\circ} \mathrm{S}$ : (a) $\partial u^{\prime} / \partial t^{+}$, (b) sum of $\left(-v^{\prime} \partial \bar{u} / \partial y\right)^{+}$ and $\left(-\bar{\omega} \partial u^{\prime} / \partial p\right)^{+}$, and (c) sum of $\left(-\bar{v} \partial u^{\prime} / \partial p\right)^{+},\left(-\omega^{\prime} \partial \bar{u} / \partial p\right)^{+}$, and $-\beta y v^{\prime+}$. The vertical dotted line indicates days when precipitation in $20^{\circ} \mathrm{N}$ reaches the maximum.

tion develops at $2^{\circ} \mathrm{S}$ at day 72 . This new convection at $2^{\circ} \mathrm{S}$ divides into the southward- and the northwardpropagating cells. While the southward-propagating convection dissipates as it reaches $10^{\circ} \mathrm{S}$ at day 84 , the northward-propagating convection intensifies until it arrives at $18^{\circ} \mathrm{N}$ at day 86 . The propagation speed of precipitation in the $2 \mathrm{D}$ model is about $4^{\circ}$ latitude day ${ }^{-1}$. Simulating the realistic period (30-90 day) and the propagating speed $\left(1^{\circ}\right.$ latitude $\left.d a y^{-1}\right)$ of BSISO in the $2 \mathrm{D}$ model is a difficult task due to the simplification involved in the 2D model. For example, the absence of the zonal divergence in 2D model results in the fast growth of horizontal divergence (convergence), since there is no cancellation between the meridional and zonal divergences during the formation of the horizontal divergence (convergence). This might be one of the reasons why the simulated BSISO exhibits the shorter period and the faster propagating speed than that of observations. Despite this limitation, the $2 \mathrm{D}$ model is successful in qualitatively reproducing the observed features of winds and precipitation associated with the northward-propagating BSISO. Thus, by examining the mechanism of the model-simulated BSISO, one can still obtain insight into the observed counterpart.

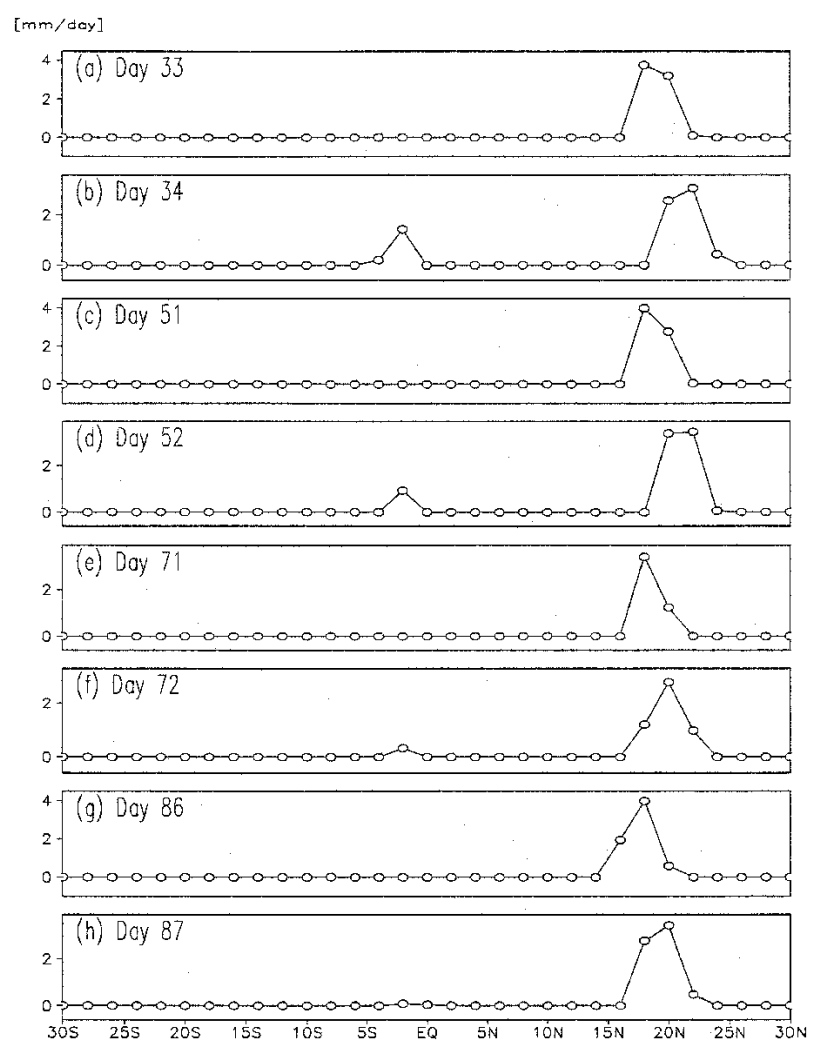

FIG. 11. Latitudinal variation of precipitation rate $\left(\mathrm{mm} \mathrm{day}^{-1}\right)$ on days (a) 33, (b) 34, (c) 51, (d) 52, (e) 71, (f) 72, (g) 86, and (h) 87 .

\section{Mechanism of northward propagation}

\section{a. Barotropic and baroclinic mode}

Understanding the mechanism of northward propagation of convection can be facilitated by analyzing the barotropic and baroclinic modes of the atmosphere. The barotropic mode $\left(\mathrm{A}^{+}\right)$and baroclinic mode $\left(\mathrm{A}^{-}\right)$ of an arbitrary variable (A) are defined as

$$
A^{+}=\frac{A_{1}+A_{2}}{2}, \quad A^{-}=\frac{A_{1}-A_{2}}{2} .
$$

Combining (1.1c), (1.2c), (9a), and (10) leads to

$$
\operatorname{Pr}=\Delta p\left(\frac{\partial v^{\prime+}}{\partial y}\right)\left(2 \bar{q}_{e}-\bar{q}_{2}\right)+\Delta p\left(\frac{\partial v^{\prime}}{\partial y}\right) \bar{q}_{2} .
$$

The first and second terms in (11) indicate the contribution of the moisture convergence associated with the barotropic and baroclinic modes of the atmosphere, respectively. In analyzing the result, the barotropic and baroclinic modes are examined separately, since the role of the barotropic and baroclinic modes on BSISO is quite different. In particular, the baroclinic mode in the 2D model enhances the intensity of the existing convection, while the barotropic mode promotes the 


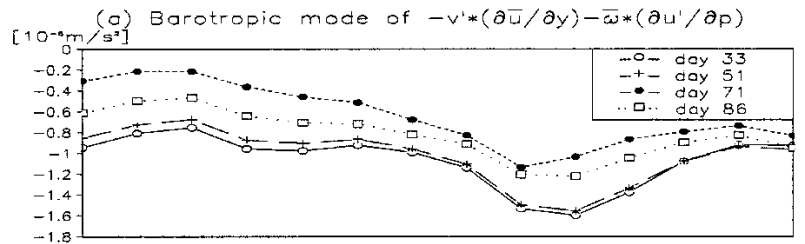

(b) Barotropic mode of $-v^{\prime} *(\partial \bar{u} / \partial y)$

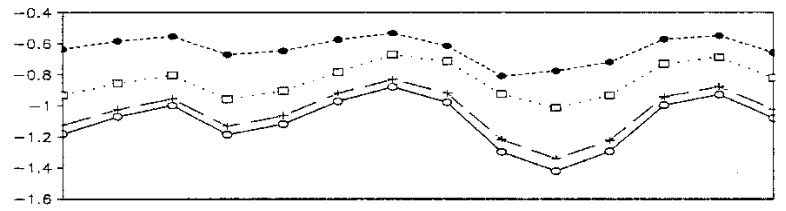

(c) Barotropic mode of $-\bar{\omega} *\left(\partial \omega^{\prime} / \partial p\right)$

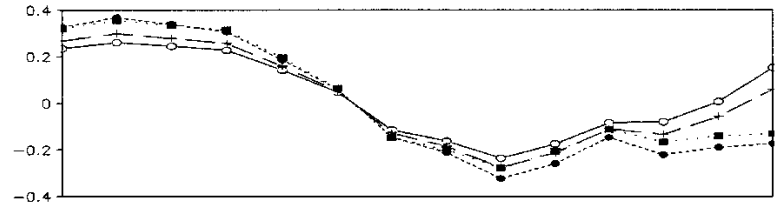

(d) Precipitation

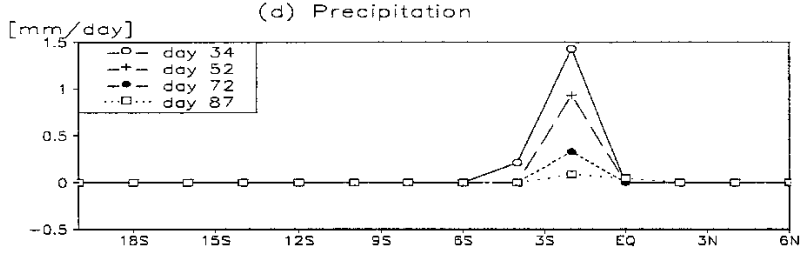

FIG. 12. Latitudinal variation of the barotropic mode of zonal momentum: (a) $\left(-v^{\prime} \partial \bar{u} / \partial y-\bar{\omega} \partial u^{\prime} / \partial p\right)^{+}$, (b) $\left(-v^{\prime} \partial \bar{u} / \partial y\right)^{+}$, (c) $\left(-\bar{\omega} \partial u^{\prime} / \partial p\right)^{+}$, and (d) precipitation.

northward propagation of convection. For example, when latent heat is released at the center of convection, horizontal divergence (convergence) develops in the upper (lower) free atmosphere. The upper-level divergence and the lower-level convergence (strengthening of the baroclinic mode) drive more moisture into the convective center, so that existing convection is intensified. The barotropic mode of atmosphere, on the other hand, causes the northward propagation of convection by inducing the boundary layer moisture convergence to the north (ahead) of existing convection (explained in the section $4 b$ ).

Shown in Fig. 5 is the baroclinic mode of moisturedivergence tendency, which can be related to the precipitation as

$$
\frac{\partial}{\partial t} \operatorname{Pr} \approx \frac{\partial}{\partial t}\left(\frac{\partial v^{\prime-}}{\partial y}\right) \bar{q}_{2} .
$$

By definition, the positive value of the baroclinic moisture-divergence tendency $\left[\partial / \partial t\left(\partial v^{\prime-} / \partial y\right) \bar{q}_{2}>0\right]$ implies the increase of precipitation with time due to the baroclinic mode. As convection propagates from $10^{\circ} \mathrm{N}$ on day 84 (Fig. $5 \mathrm{a}$ ) to $22^{\circ} \mathrm{N}$ on day 88 (Fig. 5e), the maximum of the baroclinic moisture-divergence tendency (-o-) coincides with the maximum of the precipitation rate (-+-). It implies that the baroclinic mode of atmo- (a) Barotropic $u^{\prime}$ and \& prec. rate, day 86

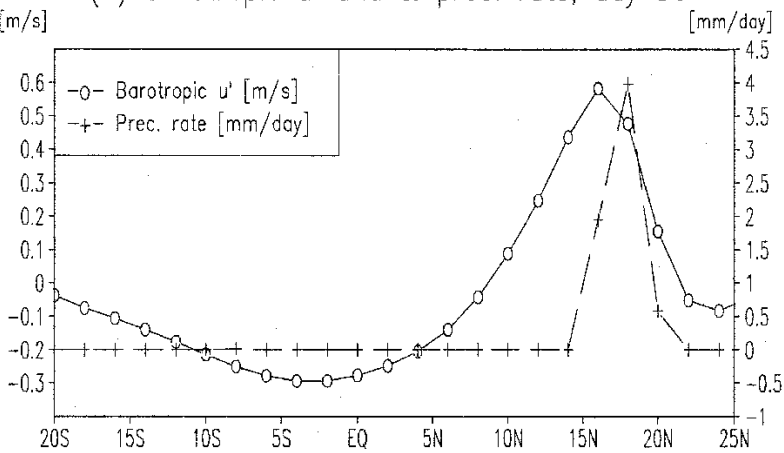

(b) Barotropic $\partial\left(-\beta y u^{1}\right) / \partial y$ and prec. rote, day 86

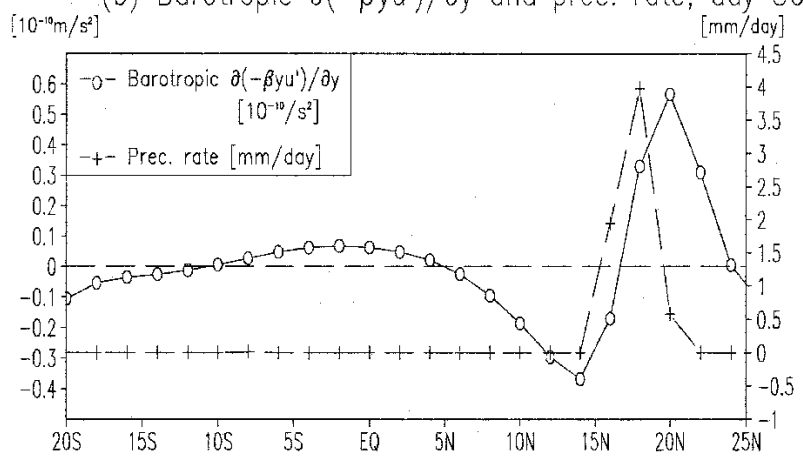

FIG. 13. Latitudinal variation of precipitation rate (-+-) and barotropic mode of (a) zonal wind anomalies $\left(u^{\prime+},-\circ-\right)$, and (b) divergence tendency induced by the Coriolis force $\left[\partial / \partial y\left(-\beta y u^{\prime+}\right)\right.$, $-\circ-]$.

sphere will enhance the precipitation where the precipitation has already obtained the maximum value. Hence, the baroclinic mode of atmosphere results in the intensification of convection, rather than inducing the propagation of convection.

The barotropic mode of moisture-divergencetendency in Fig. 6 can also be related to precipitation as

$$
\frac{\partial}{\partial t} \operatorname{Pr} \approx \frac{\partial}{\partial t}\left(\frac{\partial v^{\prime+}}{\partial y}\right)\left(2 \bar{q}_{e}-\bar{q}_{2}\right) .
$$

The most distinct feature in Fig. 6 is that the maximum of the barotropic moisture-divergence tendency (-०-) leads the maximum of the precipitation rate (-+-). It denotes that the barotropic mode of atmosphere increases (decreases) the precipitation north (south) of convection. Thus, it is the barotropic mode of atmosphere that induces the northward propagation of convection from day 84 (Fig. 6a) to 88 (Fig. 6e). In the next subsection, we examine how the barotropic mode and convection interact with each other to produce the northward propagation.

\section{b. What is the interaction between the barotropic mode of atmosphere and convection?}

The interaction between the barotropic mode and convection is made of two linkages. One involves the 
Precipitation rote $[\mathrm{mm} / \mathrm{doy}]$ for different weight in $-\bar{\omega} *\left(\partial u^{\prime} / \partial p\right)$
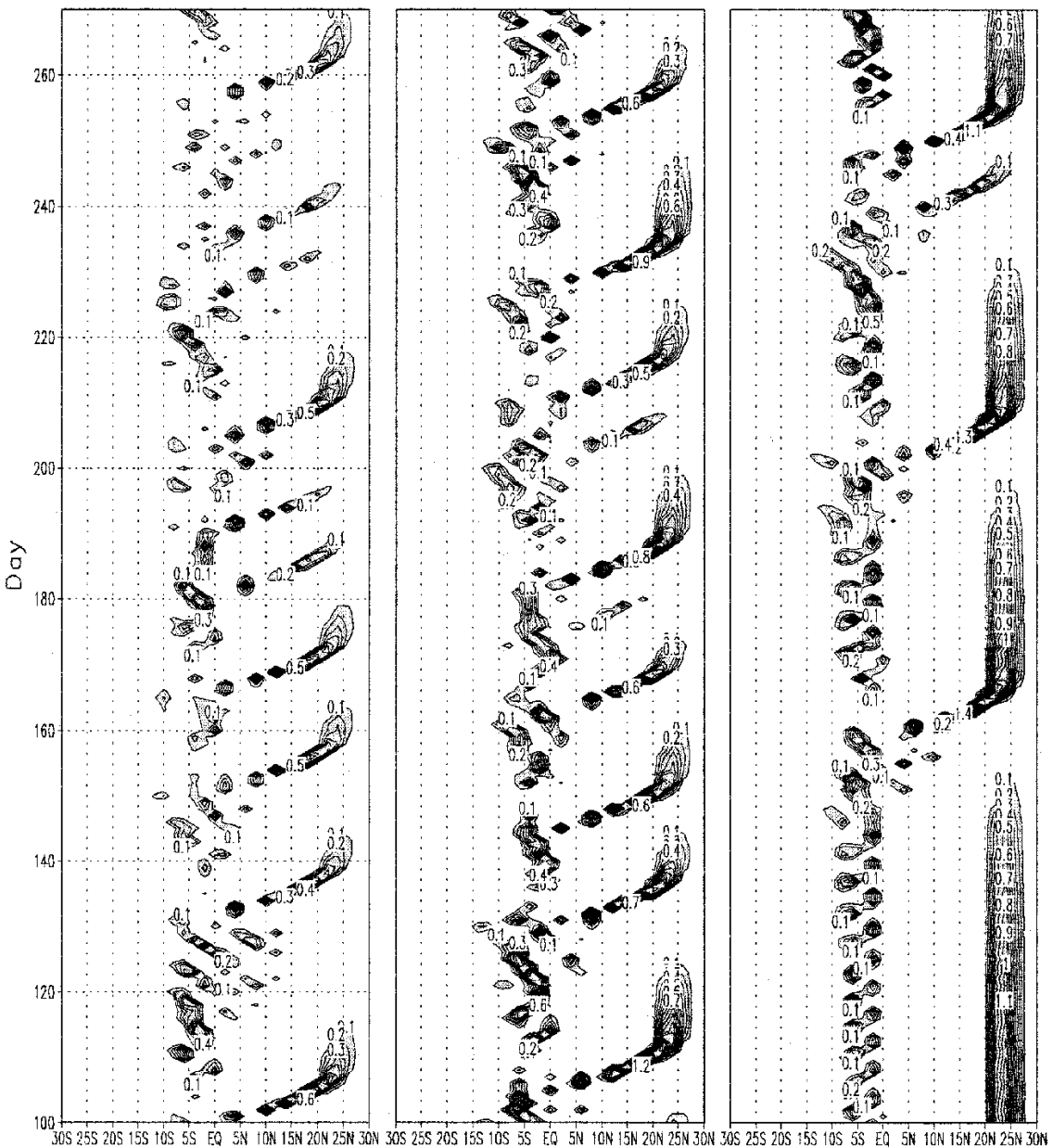

(a) $-\bar{\omega} *\left(\partial u^{\prime} / \partial p\right) * 1$

(b) $-\bar{\omega}) *\left(\partial u^{\prime} / \partial p\right) * 1,4$

(c) $-\bar{\omega} *\left(\partial u^{\prime} / \partial p\right) * 1.8$

FIG. 14. Latitude-time section of precipitation rate $\left(\mathrm{mm} \mathrm{day}^{-1}\right)$ in experiments with (a) $100 \%$ of vertical advection of anomalous zonal winds (experiment 1), (b) $140 \%$ of vertical advection of anomalous zonal winds (experiment 2), and (c) $180 \%$ of vertical advection of anomalous zonal winds (experiment 3 ) by JJA-mean vertical motion. Shading indicates precipitation greater than $0.1 \mathrm{~mm}^{-1 a y}{ }^{-1}$.

influence of the barotropic mode on convection, and the other is the feedback of convection on the barotropic mode. In the first linkage, the barotropic mode of atmosphere affects convection by controlling the moisture convergence in the boundary layer. According to (7), convergence in the boundary layer is determined by the divergence in the barotropic mode of the atmosphere. Hence, when the divergence of barotropic mode is located to the north of convection, it can generate the boundary layer moisture convergence ahead of convection, and promotes the northward migration of the BSISO.

In the feedback, convection enhances the barotropic mode of divergence $\left[\partial / \partial t\left(\partial v^{\prime+} / \partial y\right)>0\right]$ to the north of convection by controlling the barotropic mode of anomalous zonal wind $\left(u^{\prime+}\right)$. In the $2 \mathrm{D}$ model the momentum equation of meridional winds can be approximated by the sum of Coriolis force and geootential gradient force. Based on this approximation, the barotropic mode of the atmosphere can be expressed as

$$
\frac{\partial v^{\prime+}}{\partial t} \approx-\frac{\partial \phi^{\prime+}}{\partial y}-\beta y u^{\prime+}
$$

$$
\frac{\partial}{\partial t}\left(\frac{\partial{v^{\prime}}^{+}}{\partial y}\right) \approx \frac{\partial}{\partial y}\left(-\frac{\partial \phi^{\prime+}}{\partial y}\right)+\frac{\partial}{\partial y}\left(-\beta y u^{\prime+}\right) .
$$




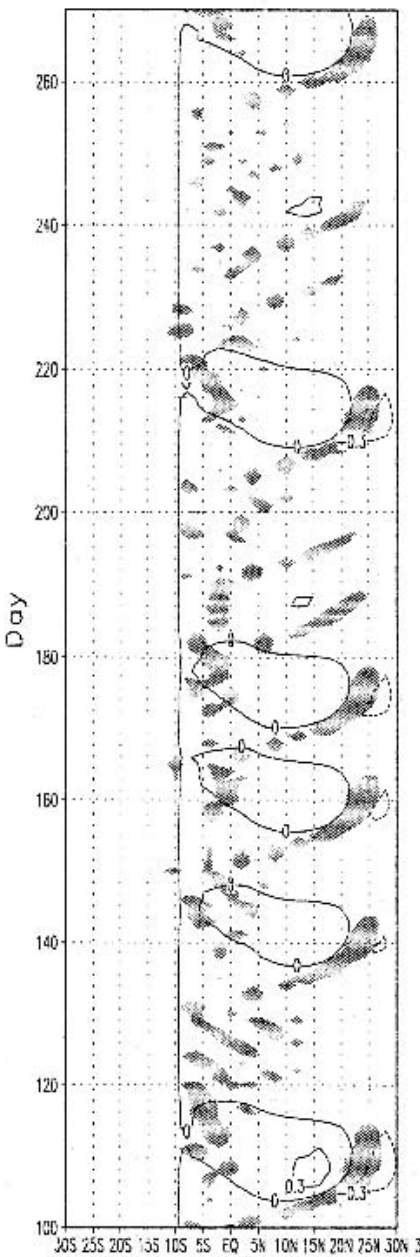

(a) Exo.1

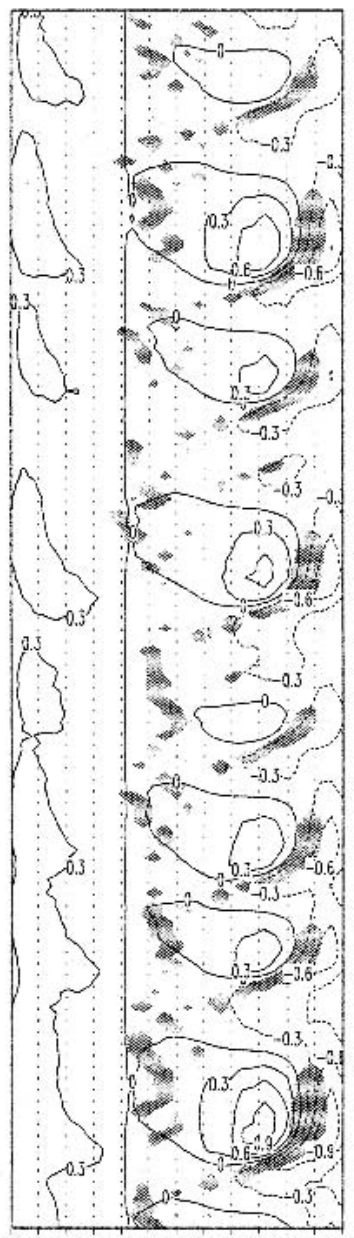

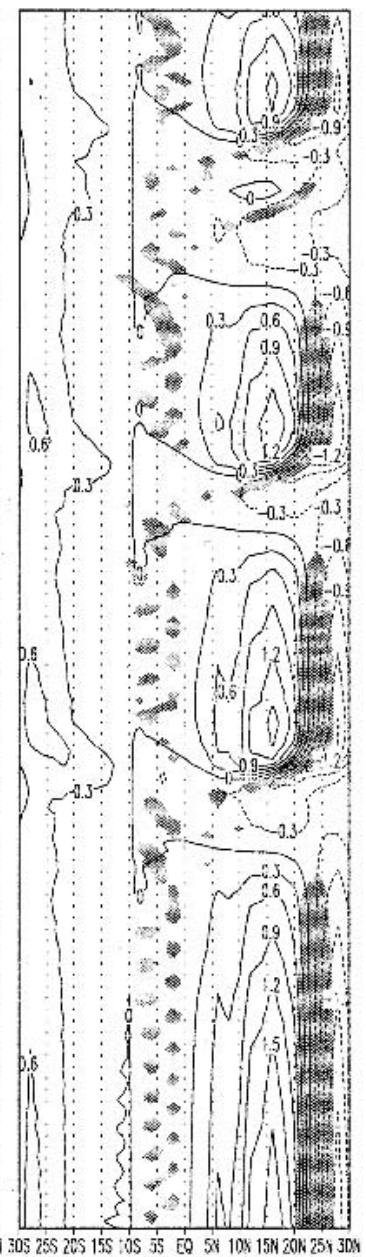

(c) $\operatorname{Exp} .3$

FIG. 15. Latitude-time section of $\left(-\bar{\omega} \partial u^{\prime} / \partial p\right)^{+}$(unit: $\left.10^{-6} \mathrm{~m} \mathrm{~s}^{-2}\right)$ in experiments (a) 1 , (b) 2 , and (c) 3. Shading indicates precipitation greater than $0.1 \mathrm{~mm} \mathrm{day}^{-1}$.

Note that the barotropic mode of divergence tendency $\left[\partial / \partial t\left(\partial v^{\prime+} / \partial y\right)\right]$ in $(14 \mathrm{~b})$ is a function of geopotential gradient force [e.g., $\left.\partial / \partial y\left(-\partial \phi^{\prime+} / \partial y\right)\right]$ and the Coriolis force [e.g., $\left.\partial / \partial y\left(-\beta y u^{\prime+}\right)\right]$. The resemblance between the meridional structures of $\partial / \partial y\left(-\beta y u^{\prime+}\right)\left(2 \bar{q}_{e}-\bar{q}_{2}\right)$ (see Fig. 7) and $\partial / \partial t\left(\partial v^{\prime+} / \partial y\right)\left(2 \bar{q}_{e}-\bar{q}_{2}\right)$ (Fig. 6), in terms of the relative location of their maximum value with respect to convection, leads the further simplification of $(14 b)$ as

$$
\frac{\partial}{\partial t}\left(\frac{\partial{v^{\prime+}}^{\prime}}{\partial y}\right) \approx \frac{\partial}{\partial y}\left(-\beta y u^{\prime+}\right) .
$$

It is indicated in (15) that convection can influence the barotropic mode of divergence by controlling the barotropic zonal winds.
Figure 8 displays a schematic diagram of this relationship. When convection is located in the Northern Hemisphere, at say $20^{\circ} \mathrm{N}$, the barotropic mode of zonal winds inside convection becomes westerlies $\left(u^{\prime+}>0\right.$, Fig. 8). The Coriolis force induced by these barotropic westerlies $\left(-\beta y u^{\prime+}<0\right.$, Fig. 8) accelerates the barotropic northerly inside convection region (14a). In response to this local acceleration of northerly at the center of convection $\left[-\beta y u^{\prime+}<0\right.$, Fig. 8, and (14a)], the barotropic divergence develops $\left[\partial / \partial y\left(-\beta y u^{\prime+}\right)>0\right.$, (15)] to the north of convection (Fig. 8). This barotropic divergence of the free atmosphere to the north of convection triggers moisture convergence in the boundary layer and facilitates the northward propagation of convection. The relationship between the barotropic divergence and the barotropic zonal winds is such that the 


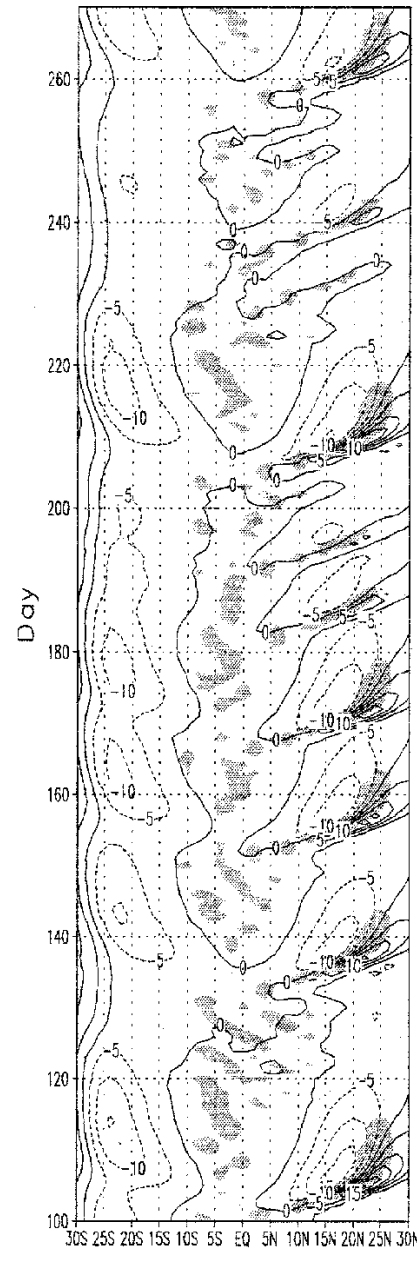

(a) Exp.1

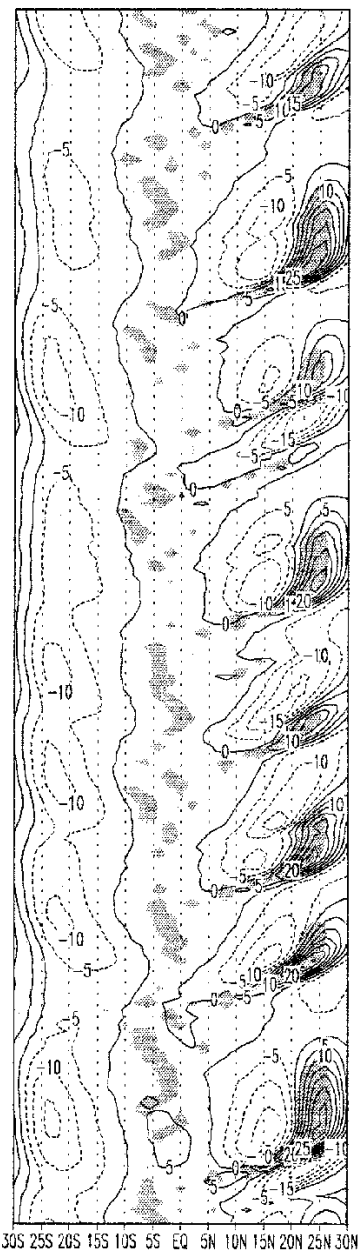

(b) Exp.2

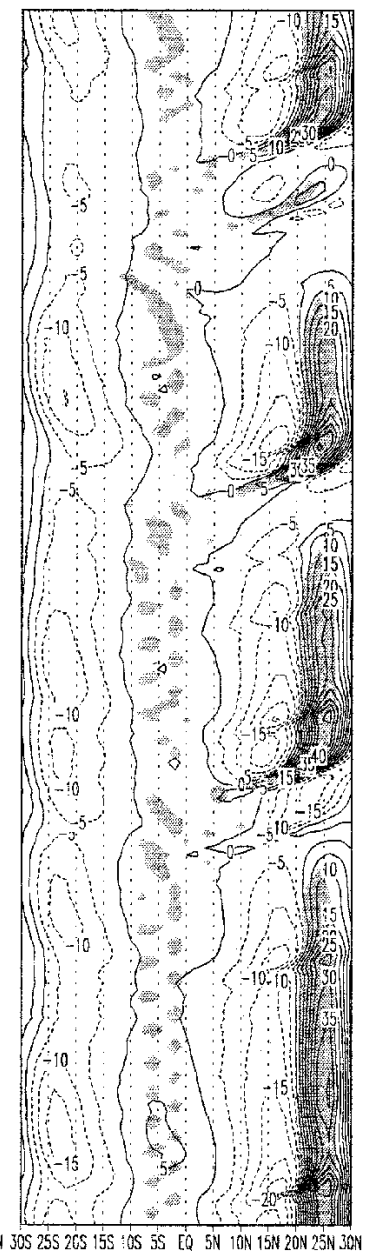

(c) Exp.3

FIG. 16. Latitude-time section of barotropic divergence tendency induced by the Coriolis force on the barotropic zonal winds $\left[\partial / \partial y\left(-\beta y u^{\prime}\right)^{+}\right]$in experiments (a) 1 , (b) 2 , and (c) 3 . The unit of $\partial / \partial y\left(-\beta y u^{\prime}\right)^{+}$is $\left(10^{-12} \mathrm{~s}^{-2}\right)$. Shading indicates precipitation greater than $0.1 \mathrm{~mm} \mathrm{day}^{-1}$.

development of barotropic westerlies inside convection is critical in order for convection to propagate northward.

The development of barotropic westerlies associated with convection can be explained by examining the barotropic mode of zonal momentum equation, which is derived by combining (1.1a), (1.2a), and (10):

$$
\begin{aligned}
\frac{\partial u^{\prime+}}{\partial t}= & \left(-\bar{v} \frac{\partial u^{\prime}}{\partial y}-v^{\prime} \frac{\partial \bar{u}}{\partial y}-\bar{\omega} \frac{\partial u^{\prime}}{\partial p}-\omega^{\prime} \frac{\partial \bar{u}}{\partial p}\right. \\
& \left.+\beta y v^{\prime}-\varepsilon u^{\prime}+K \frac{\partial^{2} u^{\prime}}{\partial y^{2}}\right)^{+} .
\end{aligned}
$$

The barotropic mode of zonal winds is controlled by each term on the rhs of (16). The relative dominance among the terms in (16) changes during different phases of convection. Especially, at the mature phase of convection the vertical advection of JJA-mean zonal winds $\left(-\omega^{\prime} \partial \bar{u} / \partial p\right)^{+}$controls the variation of zonal winds $\left(\partial u^{\prime} / \partial t^{+}\right)$. For example, shown in Fig. 9 are the barotropic modes of zonal wind tendency $\left[\left(\partial u^{\prime} / \partial t^{+}\right)\right.$, Fig. 9a], the vertical advection of JJA-mean zonal winds $\left[\left(-\omega^{\prime} \partial \bar{u} / \partial p\right)^{+}\right.$, Fig. 9b], and the sum of other components in zonal momentum equation (Fig. 9c) at $20^{\circ} \mathrm{N}$. Days 33, 52, 72, and 87 in Fig. 9 are the times when the maximum precipitation is found at $20^{\circ} \mathrm{N}$, and marked with the vertical dotted line. On those days the barotropic zonal wind tendency increases $\left[\left(\partial u^{\prime} / \partial t^{+}\right)>0\right.$, Fig. 9a] as a result of positive vertical advection of JJAmean zonal winds $\left[\left(-\omega^{\prime} \partial \bar{u} / \partial p\right)^{+}>0\right.$, Fig. 9b]. It means that when convection develops at $20^{\circ} \mathrm{N}$ the rising mo- 


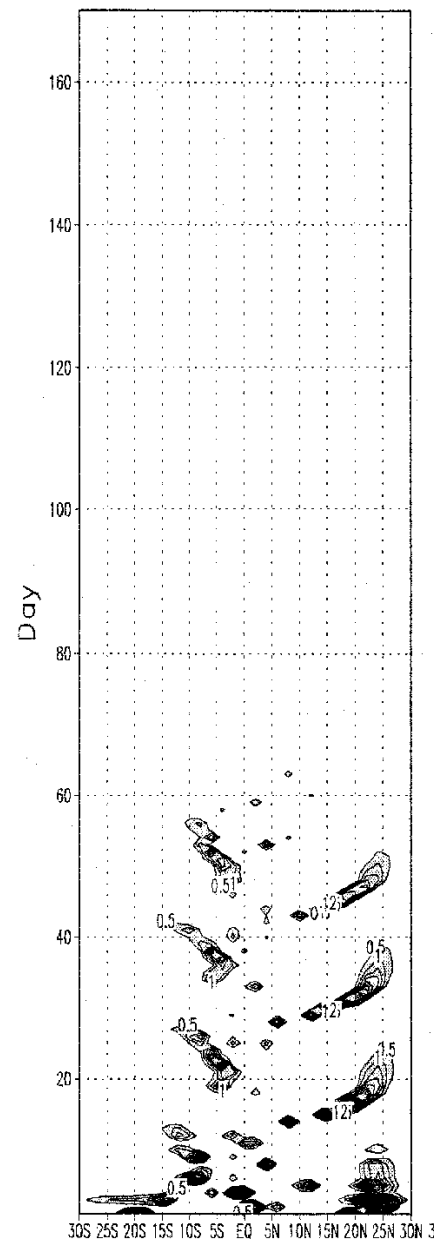

(a) $-v^{2} *(\partial \bar{u} / \partial y) * 1$

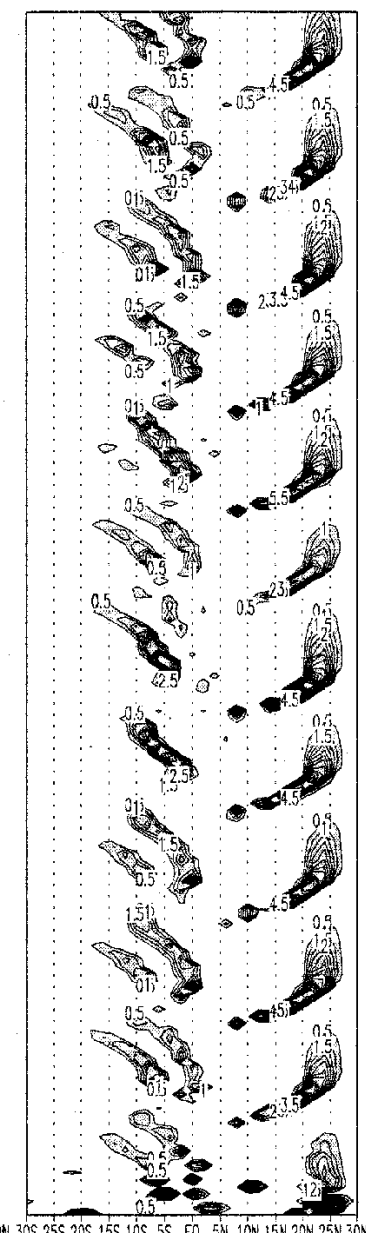

(b) $-v^{\prime} *(\partial \bar{u} / \partial y) * 1.8$

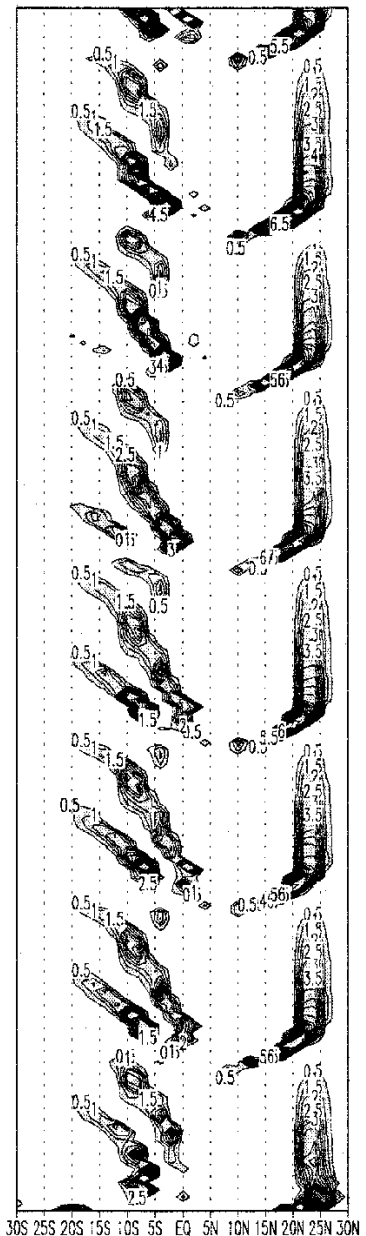

(c) $-v^{\prime} *(\partial \bar{u} / \partial y) * 2.6$

FIG. 17. Latitude-time section of precipitation rate $\left(\mathrm{mm} \mathrm{day}^{-1}\right)$ in experiments with (a) $100 \%$ of meridional advection of JJA-mean zonal winds (experiment 4 ), (b) $180 \%$ of meridional advection of JJA-mean zonal winds (experiment 5), and (c) $260 \%$ of meridional advection of JJA-mean zonal winds (experiment 6) by anomalous meridional winds. Shading indicates precipitation greater than $0.5 \mathrm{~mm}$ day $^{-1}$.

tion $\left(\omega^{\prime}<0\right)$ inside convection advects the low-level, JJA-mean westerlies $(\bar{u}>0$, Fig. 2a) throughout the layers, so that the westerly anomalies increase in both the upper and lower level of the atmosphere. Since this positive advection of JJA-mean zonal winds $\left[\left(-\omega^{\prime} \partial \bar{u} /\right.\right.$ $\partial p)^{+}>0$ ] is strongest near the convection, barotropic westerlies are often found associated with convection as illustrated in the schematic diagram (Fig. 8).

The above mechanism may also be valid in the Southern Hemisphere as long as the signs of the Coriolis parameter $(\beta y)$ and the JJA-mean vertical shear of zonal winds $(\partial \bar{u} / \partial p)$ are considered. For instance, the change in the Coriolis parameter across the equator results in the southward propagation of convection in the Southern Hemisphere, only if the underlying vertical shear of JJA-mean zonal winds is easterly $(\partial \bar{u} / \partial p>$ $0)$. When the vertical shear of the JJA-mean becomes westerly $(\partial \bar{u} / \partial p<0$, Fig. $2 c)$, as in the latitude south of $10^{\circ} \mathrm{S}$, the convection cannot propagate farther south.

\section{The development of convection south of the equator}

\section{a. Development of barotropic easterlies}

It is suggested in the previous section that the northward propagation of the BSISO depends on the vertical advection of JJA-mean zonal winds $\left[\left(-\omega^{\prime} \partial \bar{u} / \partial p\right)^{+}\right]$as- 


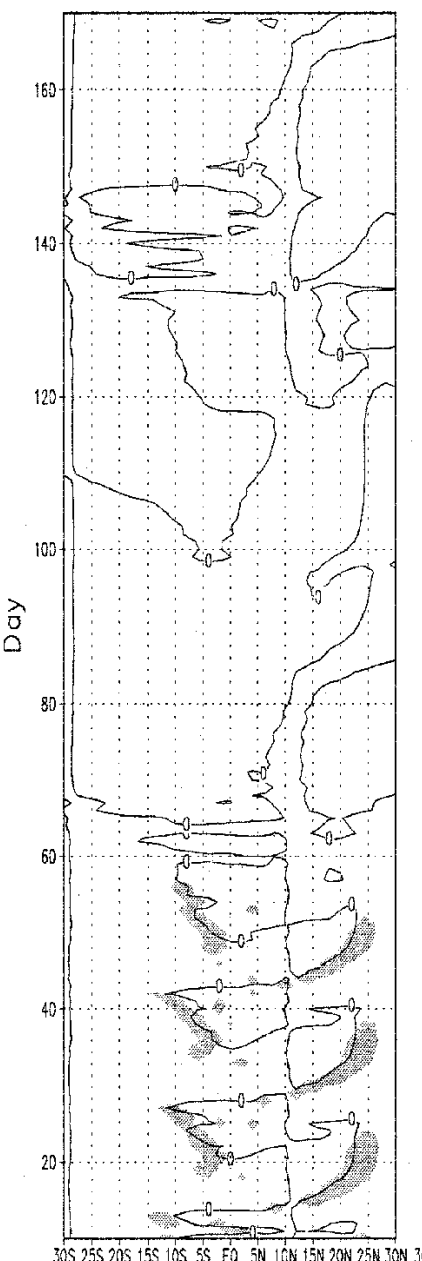

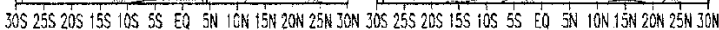
(a) Exp.4

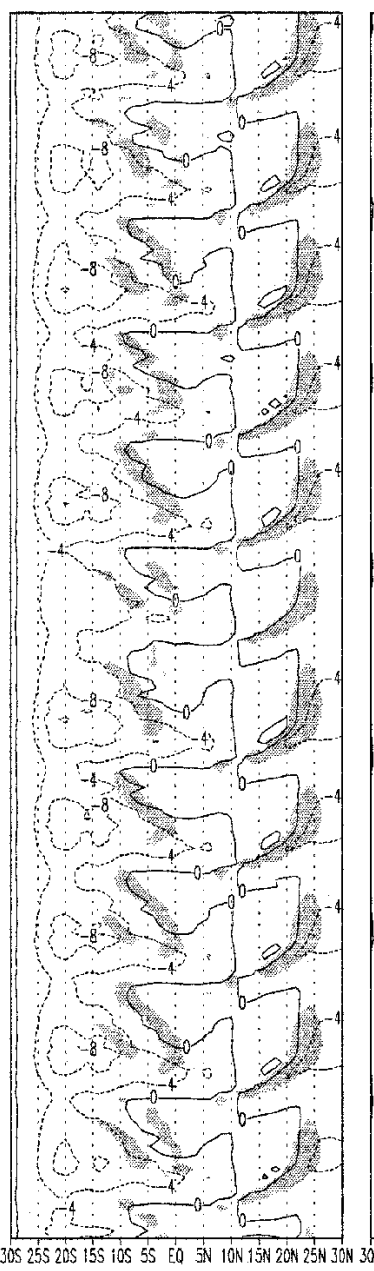

(b) Exp.5

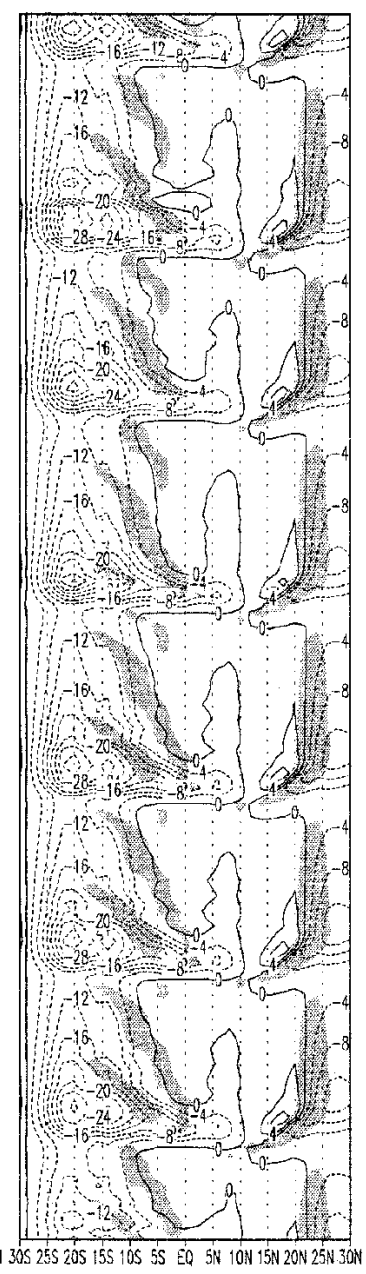

(c) Exp.6

FIG. 18. Latitude-time section of $\left(-v^{\prime} \partial \bar{u} / \partial y\right)^{+}$(unit: $\left.10^{-6} \mathrm{~m} \mathrm{~s}^{-2}\right)$ in experiments (a) 4 , (b) 5 , and (c) 6 . Shading indicates precipitation greater than $0.5 \mathrm{~mm} \mathrm{day}^{-1}$.

sociated with convection. When convection is absent or suppressed, the development of convection depends on different terms in the momentum equation (16). For example, when convection is located at $20^{\circ} \mathrm{N}$ on days $33,52,72$, and 87 , the barotropic mode of zonal momentum $\left(\partial u^{\prime} / \partial t^{+}\right.$, Fig. 10a) at $4^{\circ} \mathrm{S}$ becomes governed by the sum of $\left(-\bar{\omega} \partial u^{\prime} / \partial p\right)^{+}$and $\left(-v^{\prime} \partial \bar{u} / \partial y\right)^{+}$(Fig. 10b). That is the increase of barotropic easterlies $\left(\partial u^{\prime} / \partial t^{+}<\right.$ 0 , Fig. 10a) on days $34,52,72$, and 87 , which are the developing days of convection at $2^{\circ} \mathrm{S}$ (Figs. 11b,d,f,h), is caused by the minimum value of $\left(-\bar{\omega} \partial u^{\prime} / \partial p\right)^{+}$and $\left(-v^{\prime} \partial \bar{u} / \partial y\right)^{+}$(Fig. 10b).

In Fig. 12, the meridional structure of these two terms are shown in an attempt to find out the spatial structure that is responsible for the development of convection at $2^{\circ} \mathrm{S}$. The local minimum in the sum of $\left(-\bar{\omega} \partial u^{\prime} / \partial p\right)^{+}$and $\left(-v^{\prime} \partial \bar{u} / \partial y\right)^{+}$is found around $3^{\circ} \mathrm{S}$ (Fig. 12a). This indicates that the total effect of $\left(-\bar{\omega} \partial u^{\prime} /\right.$ $\partial p)^{+}$and $\left(-v^{\prime} \partial \bar{u} / \partial y\right)^{+}$results in the maximum increase of the barotropic easterlies $\left(\partial u^{\prime} / \partial t^{+}<0\right)$ around $3^{\circ} \mathrm{S}$. While $\left(-v^{\prime} \partial \bar{u} / \partial y\right)^{+}$produces the secondary minimum at $14^{\circ} \mathrm{S}$ (Fig. 12b), the term $\left(-\bar{\omega} \partial u^{\prime} / \partial p\right)^{+}$(Fig. 12c) induces one distinct minimum at $4^{\circ} \mathrm{S}$. Particularly, the latitude $4^{\circ} \mathrm{S}$ is preferred, since the rising motion of the JJA-mean vertical pressure velocity in the Southern Hemisphere is locally maximum at $4^{\circ} \mathrm{S}(\bar{\omega}<0$, Fig. $2 \mathrm{~d})$, where the momentum of low-level anomalous easterlies ( $u^{\prime}<0$, Fig. 3b) is transported throughout the layers $\left[\left(-\bar{\omega} \partial u^{\prime} / \partial p\right)^{+}<0\right]$ increasing the barotropic easterlies mostly at $4^{\circ} \mathrm{S}$. 

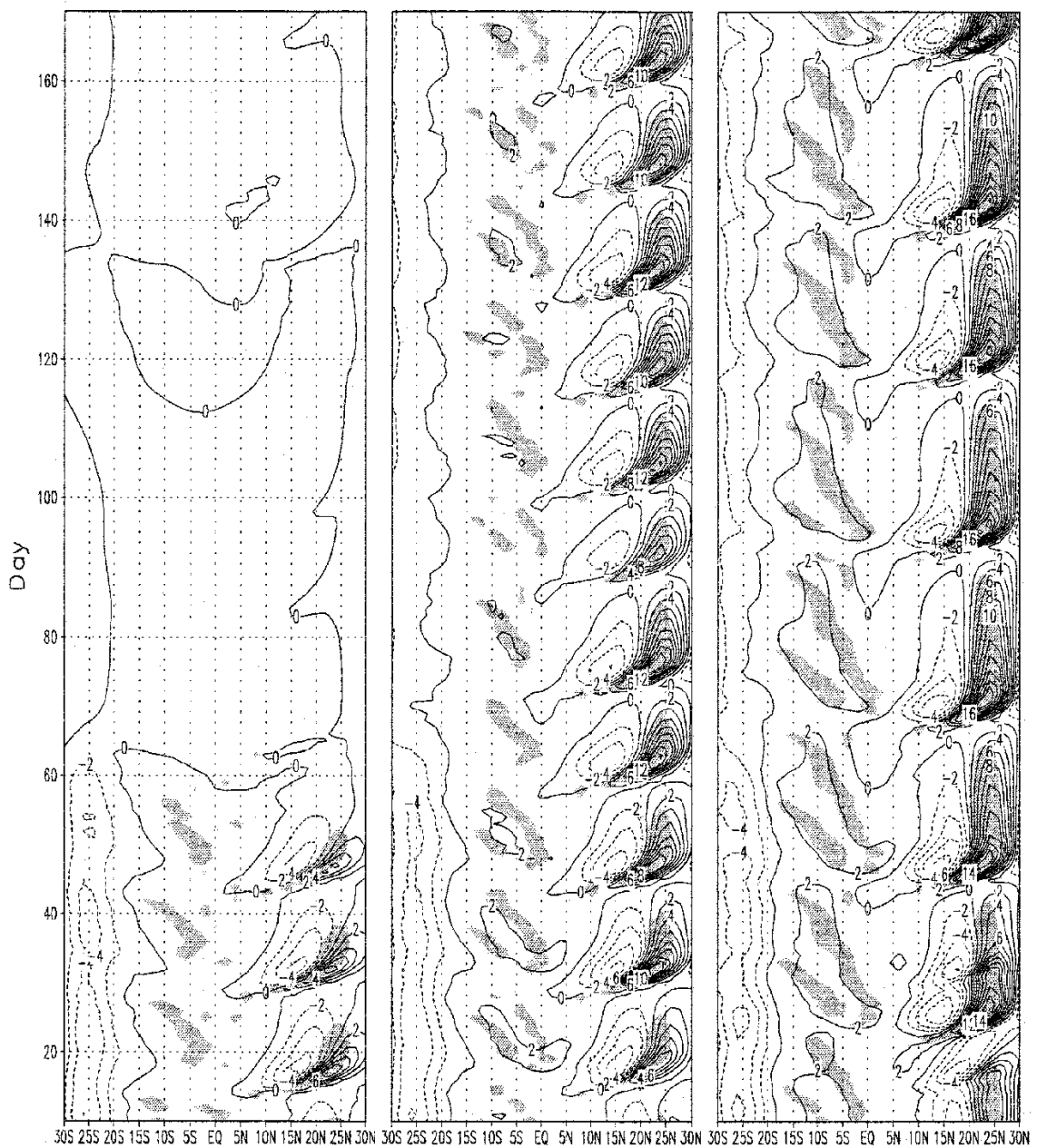

(a) Exp.4

(b) Exp.5

(c) Exp.6

FIG. 19. Latitude-time section of barotropic divergence tendency induced by the Coriolis force on the barotropic zonal winds $\left[\partial / \partial y\left(-\beta y u^{\prime}\right)^{+}\right]$in experiments (a) 4 , (b) 5 , and (c) 6 . The unit of $\partial / \partial y\left(-\beta y u^{\prime}\right)^{+}$is $\left(10^{-11} \mathrm{~s}^{-2}\right)$. Shading indicates precipitation greater than $0.5 \mathrm{~mm}$ day $^{-1}$.

\section{b. Roles of barotropic easterlies in the development of convection}

When the increase of easterly momentum by $-v^{\prime}(\partial \bar{u} /$ $\partial y)$ and $-\bar{\omega}\left(\partial u^{\prime} / \partial p\right)$ results in the local maximum of barotropic easterlies near $4^{\circ} \mathrm{S}$ on day $86\left(u^{\prime+} \ll 0\right.$, Fig. 13a), these barotropic easterlies induce the barotropic divergence $\left[\partial / \partial y\left(-\beta y u^{\prime}\right)^{+}>0\right]$ in the latitude between $10^{\circ} \mathrm{S}$ and $5^{\circ} \mathrm{N}$ (Fig. 13b). The barotropic divergence in these latitudes, in turn, triggers the boundary layer convergence, which promotes the development of new convection in the latitude between $10^{\circ} \mathrm{S}$ and $5^{\circ} \mathrm{N}$.

The physical meaning of $\left[\partial / \partial y\left(-\beta y u^{\prime}\right)^{+}\right]$can be examined by dividing this term into $\left(-\beta u^{\prime+}\right)$ and $\beta y^{*}\left(-\partial u^{\prime+} / \partial y\right)$. That is,

$$
\frac{\partial}{\partial t}\left(\frac{\partial{v^{\prime}}^{+}}{\partial y}\right) \approx \frac{\partial}{\partial y}\left(-\beta y u^{\prime+}\right)=-\beta u^{\prime+}+\beta y\left(-\frac{\partial u^{\prime+}}{\partial y}\right) .
$$

The term $\left(-\beta u^{\prime+}\right)$ in (17) implies that the barotropic easterlies $\left(u^{\prime+}<0\right)$ can increase the barotropic divergence $\left[\partial / \partial t\left(\partial v^{\prime+} / \partial y\right)>0\right]$. According to the term $\left(-\beta u^{\prime+}\right)$, the barotropic divergence must increase in the whole latitude between $20^{\circ} \mathrm{S}$ and $6^{\circ} \mathrm{N}$ on day 86 (Fig. 13a). However, because of the impact of the shear vorticity of the barotropic easterlies $\left(-\partial u^{\prime+} / \partial y\right)$ the latitude of $\left[(\partial / \partial y)\left(-\beta y u^{\prime}\right)^{+}>0\right]$ is further confined on day 86 (Fig. 13b). 
Precipitation rote $[\mathrm{mm} /$ day $]$ for different weight in $-\omega^{\prime} *(\partial \bar{u} / \partial p)$

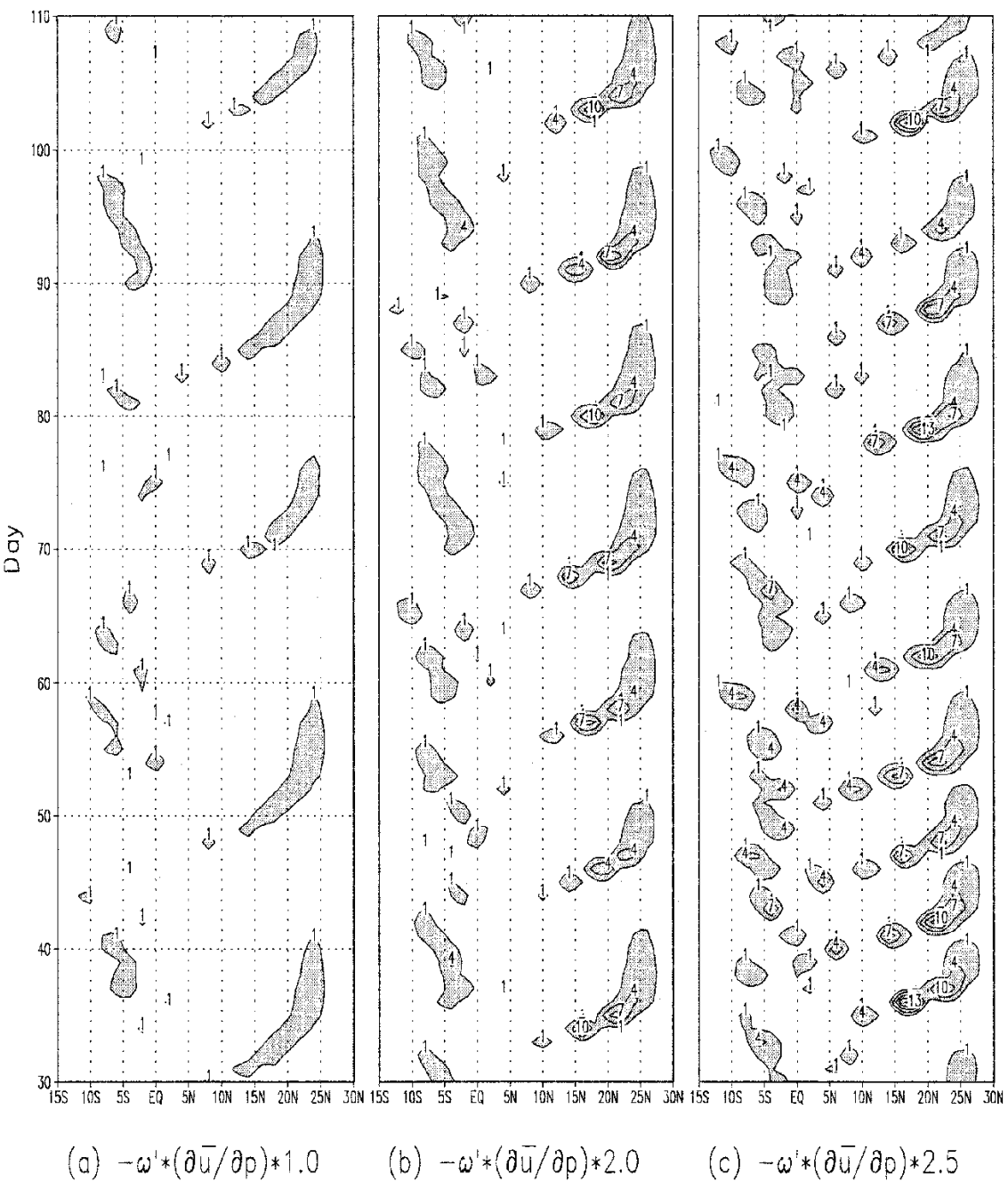

FIG. 20. Latitude-time section of precipitation rate $\left(\mathrm{mm} \mathrm{day}^{-1}\right)$ in experiments with (a) $100 \%$ of vertical advection of JJA-mean zonal winds (experiment 7 ), (b) $200 \%$ of vertical advection of JJA-mean zonal winds (experiment 8 ), and (c) $250 \%$ of vertical advection of JJA-mean zonal winds (experiment 9) by the anomalous vertical motion. Shading indicates precipitation greater than $1 \mathrm{~mm}$ day $^{-1}$.

\section{Further numerical experiments}

The analysis of the simulated BSISO in the 2D model suggests that $\left(-\bar{\omega} \partial u^{\prime} / \partial p\right)$ and $\left(-v^{\prime} \partial \bar{u} / \partial y\right)$ control the development of convection in the Southern Hemisphere, while $\left(-\omega^{\prime} \partial \bar{u} / \partial p\right)$ causes the propagation of convection in the Northern Hemisphere. In this section, this hypothesis is examined by using nine experiments. In the nine numerical experiments, the JJA-mean vertical advection of anomalous zonal winds $\left(-\bar{\omega} \partial u^{\prime} / \partial p\right)$, the anomalous meridional advection of JJA-mean zonal winds $\left(-v^{\prime} \partial \bar{u} / \partial y\right)$, and the anomalous vertical advection of JJA-mean zonal winds $\left(-\omega^{\prime} \partial \bar{u} / \partial p\right)$ are artificially enhanced or reduced.

\section{a. The effect of $\left(-\bar{\omega} \partial u^{\prime} / \partial p\right)$ on the BSISO (experiments 1, 2, and 3)}

In experiments 1,2 , and 3 the JJA-mean vertical advection of anomalous zonal winds $\left(-\bar{\omega} \partial u^{\prime} / \partial p\right)$ is designed to be $100 \%$ (experiment 1 ), $140 \%$ (experiment 2 ), and $180 \%$ (experiment 3 ) of the original value, while $\left(-v^{\prime} \partial \bar{u} / \partial y\right)$ is set to be zero (experiments 1,2 , and 3) throughout these experiments. By comparing results among experiments 1,2 , and 3 , one may identify the effect of the JJA-mean vertical advection of anomalous zonal winds on the intraseasonal oscillation. When the magnitude of $\left(-\bar{\omega} \partial u^{\prime} / \partial p\right)$ is increased from $100 \%$ (Fig. 14a) to $180 \%$ (Fig. 14c) the frequency of convec- 
tion decreases, while the intensity of convection increases.

As $\left(-\bar{\omega} \partial u^{\prime} / \partial p\right)$ becomes dominant (experiment 3; Fig. 15c), it accelerates the barotropic westerlies $\left(-\bar{\omega} \partial u^{\prime} / \partial p>0\right)$ and the barotropic easterlies $\left(-\bar{\omega} \partial u^{\prime} / \partial p\right.$ $<0)$ to the south and to the north of convection, respectively. Accordingly, the positive barotropic shear vorticity $\left(-\partial u^{\prime+} / \partial y>0\right.$, Fig. 23a) develops in between, inducing barotropic divergence at $24^{\circ} \mathrm{N}\left[\partial\left(-\beta y u^{\prime}\right)^{+} / \partial y\right.$ $>0$, Fig. $16 \mathrm{c}]$. As a result, the life span of convection at $24^{\circ} \mathrm{N}$ is extended, causing the low frequency of the BSISO in experiment 3.

\section{b. The effect of $\left(-v^{\prime} \partial \bar{u} / \partial y\right)$ on the BSISO (experiments 4, 5, and 6)}

In experiments 4,5 , and $6\left(-\bar{\omega} \partial u^{\prime} / \partial p\right)$ is set to be zero, and $\left(-v^{\prime} \partial \bar{u} / \partial y\right)$ is weighted as $100 \%$ (experiment 4), $180 \%$ (experiment 5), and $260 \%$ (experiment 6 ) of the original value. When $\left(-v^{\prime} \partial \bar{u} / \partial y\right)$ is weighted as $100 \%$ the initial disturbances are dissipated by day 58 (Fig. 17a). As $\left(-v^{\prime} \partial \bar{u} / \partial y\right)$ is enhanced to be $260 \%$ the intensity of the BSISO increases while the frequency decreases (Fig. 17c). Similar to the case of experiment 3 , the reduced frequency of the BSISO in experiment 6 seems to be related with the local acceleration of the barotropic westerly at $18^{\circ} \mathrm{N}$ and the barotropic easterly at $28^{\circ} \mathrm{N}$ (Fig. 18c). The resultant positive shear vorticity (Fig. 23a) generates the barotropic divergence (Fig. $19 \mathrm{c})$ in the region of convection, so that the period of the BSISO, as well as the duration of convection, is extended. In the Southern Hemisphere, the maximum barotropic easterly at $20^{\circ} \mathrm{S}$ (Fig. 18c) enhances the barotropic divergence between $15^{\circ} \mathrm{S}$ and the equator (Fig. 19c). Consequently, the convection in the Southern Hemisphere becomes well organized in experiment 6 .

\section{c. The effect of $\left(-\omega^{\prime} \partial \bar{u} / \partial p\right)$ on the BSISO (experiments 7, 8, and 9)}

In experiments 7,8 , and 9 the weight of the anomalous vertical advection of JJA-mean zonal winds $\left(-\omega^{\prime} \partial \bar{u} / \partial p\right)$ is changed from $100 \%$ to $250 \%$ of its original value. As the weight of vertical advection increases from $100 \%$ (Fig. 20a) to $250 \%$ (Fig. 20c), the frequency, propagating speed, and intensity of convection increase. The increase of the frequency in experiment 9 is different from the previous experiments where the frequency decreases as the intensity of convection increases (experiments 3 and 6).

This discrepancy between experiments 3, 6, and 9 may be caused by the different dissipating rates of convection. For, example, when convection is located at $22^{\circ} \mathrm{N}$ in experiments 3 (Fig. 21a) and 6 (Fig. 21b) it becomes stationary before it dissipates. On the other hand, convection in experiment 9 (Fig. 21c) keeps propagating northward. The northward-propagating convection might have a faster dissipating rate, since

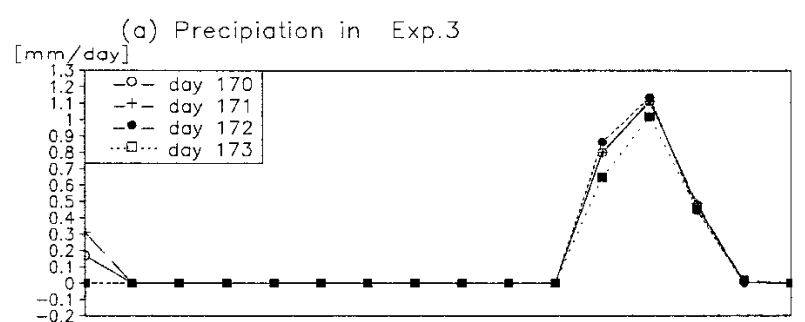

(b) Precipiation in Exp.6

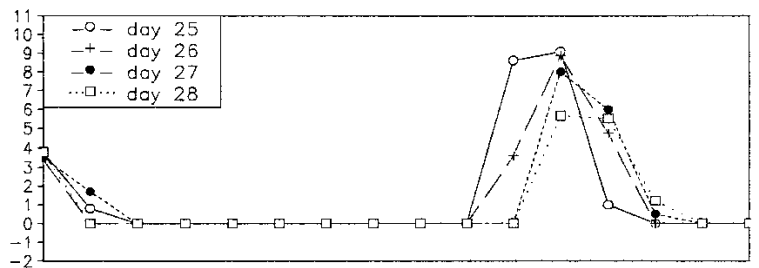

(c) Precipiation in Exp.9

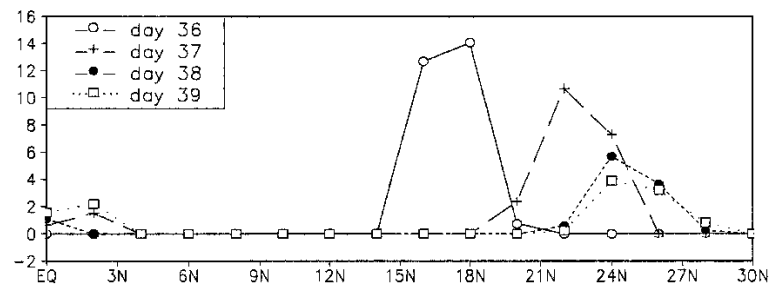

FIG. 21. Latitudinal variation of precipitation $\left(\mathrm{mm} \mathrm{day}{ }^{-1}\right)$ in experiments (a) 3, (b) 6, and (c) 9 .

the specific humidity decreases to the north of $20^{\circ} \mathrm{N}$. As a result, the life span of convection is shorter in experiment 9 than in experiments 3 and 6 , and the BSISO in experiment 9 has the highest frequency among these experiments.

The stationary versus propagating characteristics of convection at $22^{\circ} \mathrm{N}$ depends on the development of the barotropic zonal winds adjacent to convection. When $\left(-\omega^{\prime} \partial \bar{u} / \partial p\right)^{+}$is dominant in experiment 9 (Fig. 22c), the maximum barotropic westerlies develop at the center of convection in $22^{\circ} \mathrm{N}$. This maximum barotropic westerlies produce the negative (positive) barotropic shear vorticity to the south (north) of convection (Fig. 23b), resulting in the northward propagation of convection. On the contrary, in the cases of experiments 3 and 6 convection at $22^{\circ} \mathrm{N}$ generates the maximum barotropic westerlies (easterlies) to the south (north) of the convective center (Figs. 15c, 18c, and 23a). Consequently, the positive barotropic shear vorticity $\left(-\partial u^{\prime+} / \partial y>0\right)$ develops in the region of convection (Fig. 23a), enhancing the stationary characteristics of convection.

\section{Conclusions and discussion}

The mechanism of the boreal summer intraseasonal oscillation (northward propagation and development in the equatorial Indian Ocean) is examined using a zonally symmetric model (2D model). The difference be- 


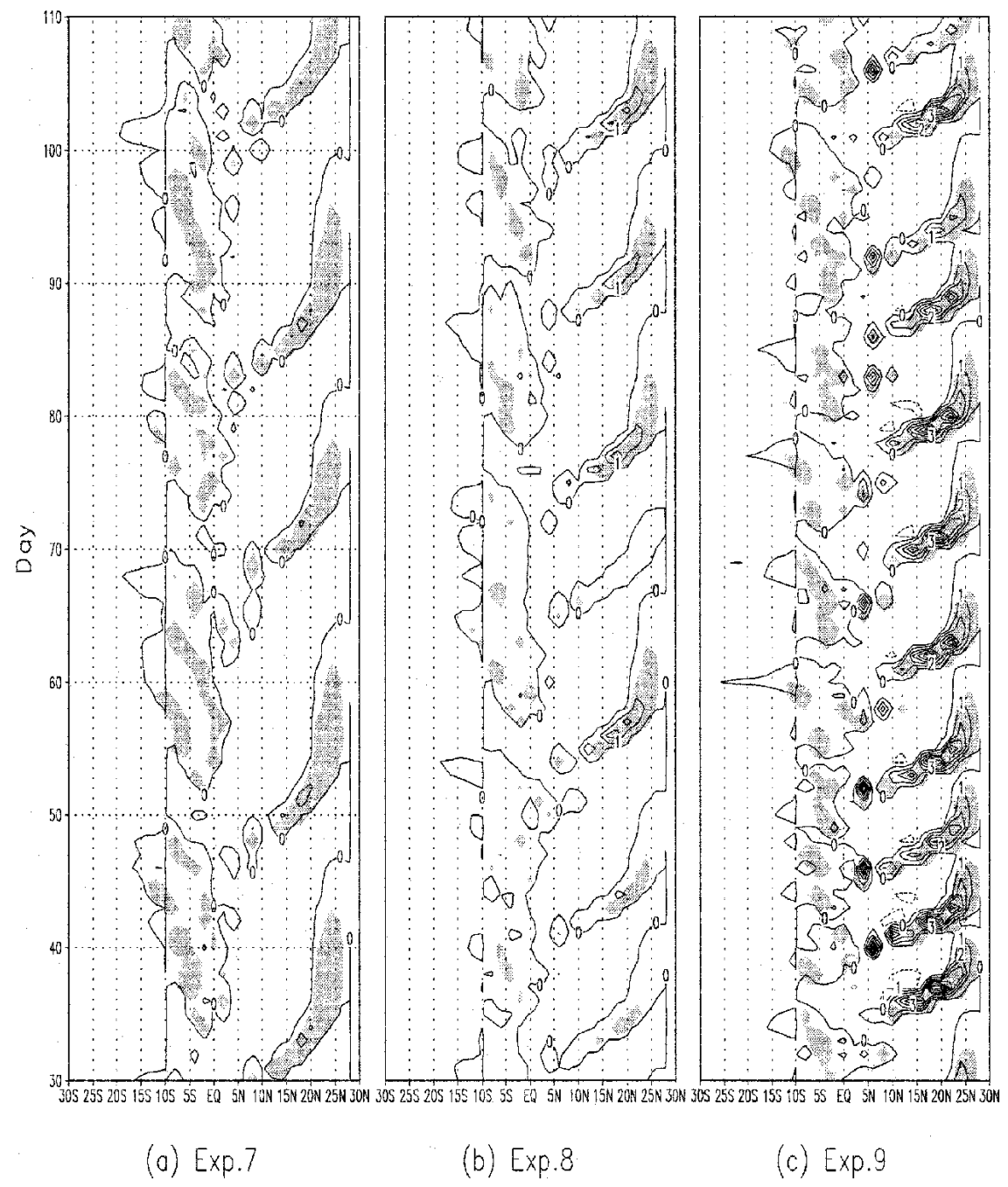

FIG. 22. Latitude-time section of $\left(-\omega^{\prime} \partial \bar{u} / \partial p\right)^{+}$(unit: $10^{-5} \mathrm{~m} \mathrm{~s}^{-2}$ ) in experiments (a) 7 , (b) 8 , and (c) 9 . Shading indicates precipitation greater than $1 \mathrm{~mm} \mathrm{day}^{-1}$.

tween this study and previous modeling studies is that the zonally propagating wave effect is excluded in order to focus on the role of other atmospheric processes on the development and northward propagation of convection. It should be noticed that the mechanism of the development and the northward propagation of convection is suggested in terms of the interaction between the anomalous winds of the BSISO and the JJA-mean winds. Thus, the developing and propagating mechanism by $\left(-\bar{\omega} \partial u^{\prime} / \partial p\right)^{+},\left(-v^{\prime} \partial \bar{u} / \partial y\right)^{+}$, and $\left(-\omega^{\prime} \partial \bar{u} / \partial p\right)^{+}$ should be interpreted as the mechanism that focuses on the effect of the monsoon mean flow on the northward propagation of the BSISO.

The analysis of the barotropic and baroclinic modes of the atmosphere reveals that the baroclinic mode is important for the intensification of convection, whereas the barotropic mode causes the propagation and initiation of convection. The upward motion at the center of convection advects JJA-mean zonal winds $\left(-\omega^{\prime} \partial \bar{u} / \partial p\right)$, and induces barotropic divergence to the north of the convective center. This barotropic divergence is compensated by boundary layer convergence, which increases the convective available potential energy and moisture supply that favor the northward movement of convection.

Meanwhile, the northward-propagating convection generates the local Hadley-type circulation, whose anomalous winds in the Southern Hemisphere interact with the JJA-mean vertical motion $\left(-\bar{\omega} \partial u^{\prime} / \partial p\right)$ and the JJA-mean zonal motion $\left(-v^{\prime} \partial \bar{u} / \partial y\right)$ to produce the barotropic divergence to the south of the equator. Accordingly, moisture in the boundary layer converges in 


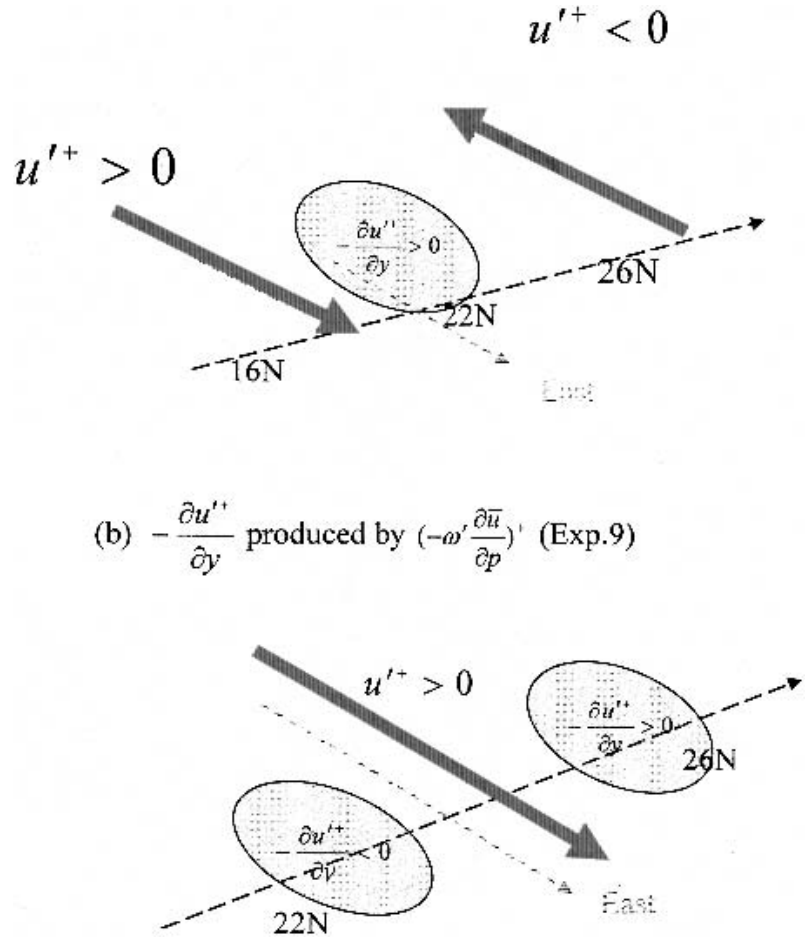

FIG. 23. Schematic diagram of the shear vorticity $\left[\left(-\partial u^{\prime} / \partial y\right)^{+}\right.$, green area] in experiments (a) 3 and 6, and (b) 9 .

that region and develops new convection in the Southern Hemisphere.

It is shown in the numerical experiments that the amplification of $\left(-\bar{\omega} \partial u^{\prime} / \partial p\right)$ and $\left(-v^{\prime} \partial \bar{u} / \partial y\right)$ extends the life span of convection, and hence increases the period of the BSISO. On the other hand, when the anomalous vertical advection of time-mean zonal winds $\left(-\omega^{\prime} \partial \bar{u} /\right.$ $\partial p$ ) becomes dominant it increases the propagation speed and reduces the period of the BSISO. Ultimately, the barotropic mode of anomalous shear vorticity adjacent to convection seems to control the propagation and the period of convection.

The 2D model that simulated the BSISO has several shortcomings. First, the specific humidity of atmosphere is fixed to the JJA-mean value. Hence, in the model simulation the supply of moisture to convection is unlimited as long as the convergence (divergence) exists in the lower (upper) atmosphere. As a consequence, the baroclinic mode (lower-level convergence and upper-level divergence) in the $2 \mathrm{D}$ model continuously supplies the convective area with moisture. In nature, however, convection dissipates when all the available moisture in the lower level and the boundary layer of atmosphere is consumed. It implies that precipitation, induced by the baroclinic mode of atmosphere, can deplete the moisture in the atmosphere and stop the further intensification of convection in nature. Therefore, in reality the baroclinic mode of atmosphere might indirectly affect the propagation of convection.
Second, the simulated northward propagation of convection is discontinuous across the equator. This might be linked to the little influence of the baroclinic mode on the propagation of convection in the $2 \mathrm{D}$ model. The barotropic mode of atmosphere, alone, cannot produce the propagation of convection across the equator since the Coriolis parameter is zero $(\beta y \approx 0)$ at the equator. As a result, the development of barotropic divergence $\left[\partial / \partial y\left(-\beta y u^{\prime+}\right) \geq 0,(15)\right]$ becomes trivial across the equator. The question of how the baroclinic mode of atmosphere affects the propagation of convection across the equator remains unanswered and is being pursued in another study.

The other unrealistic feature of BSISO in the 2D model is its fast propagation and short period (15-20 day). It is speculated that the absence of zonal divergence in 2D model might cause the rapid increase of barotropic divergence, which leads to the quick development and the propagation of convection. For example, for the intraseasonal time scale, the zonal component of the divergence can balance out the meridional component, so that the amplitude of the horizontal divergence becomes smaller than that of meridional component. Hence, in the $2 \mathrm{D}$ model, the divergence that depends only on the meridional component could be overestimated.

The exclusion of the east-west migration in the 2D model might also be responsible for the short period of the BSISO. According to Wang and Xie (1997), the life cycle of the BSISO, simulated in the three-dimensional model spans a month, including the equatorial eastward propagation of a coupled Kelvin-Rossby wave packet, an emanation of moist Rossby waves in the western Pacific, the westward propagation of the Rossby wave, and the reinitiation of the equatorial disturbance. Among these processes, the eastward propagation of the Kelvin-Rossby wave packet and the westward propagation of the Rossby wave are not included in the 2D model. Consequently, the omission of the duration for such processes shortens the period of the BSISO in the 2D model.

Despite the above deficiencies in the modelsimulated BSISO, the implication of the physical mechanism suggested in this study contributes to our understanding of the intraseasonal oscillation. The roles of baroclinic and barotropic modes on the northward-propagating BSISO and its interaction within convection provide a new perspective. Due to the strong baroclinic mode imbedded in the intraseasonal anomalies, researchers have focused on the baroclinic nature of intraseasonal oscillation. Furthermore, the linkage between the time-mean atmospheric circulation and the northward propagation of convection in the atmospheric intrinsic dynamics, independent of the equatorial wave dynamics, has not been explored. Thus, the role of the monsoon mean field in establishing the barotropic mode of the BSISO is a new finding from this study. 
Acknowledgments. This study has been supported by the Climate Dynamics Program of the National Science Foundation (ATMoo-73023). The authors thank Dr. Tim Li for his insightful comments and valuable suggestions during the course of the research.

\section{REFERENCES}

Anderson, J. R., and D. E. Stevens, 1987: The presence of linear wavelike modes in a zonally symmetric model of the tropical atmosphere. J. Atmos. Sci., 44, 2115-2127.

Chen, T.-C., and T. Murakami, 1988: The 30-50-day variation of convective activity over the western Pacific Ocean with emphasis on the northwestern region. Mon. Wea. Rev., 116, 892906.

Drbohlav, H.-K., 2002: The mechanism of intraseasonal oscillation in the south Asian monsoon region. Ph.D. dissertation, University of Hawaii at Manoa, 240 pp.

Gadgil, S., and J. Srinivasan, 1990: Low frequency variation of tropical convergence zones. Meteor. Atmos. Phys., 44, 119132.

Gautier, C., and B. DiJulio, 1990: Cloud effects on air-sea interactions during the 1979 Indian summer monsoon as studies from satellite observation. Meteor. Atmos. Phys., 44, 251-263.

Goswami, B. N., and J. Shukla, 1984: Quasi-periodic oscillations in a symmetrical general circulation model. J. Atmos. Sci., 41, 20-37.

Hartmann, D. L., and M. L. Michelsen, 1989: Intraseasonal periodicities in Indian rainfall. J. Atmos. Sci., 46, 2838-2862.

$\mathrm{Hu}$, Q., and D. A. Randall, 1994: Low-frequency oscillations in radiative-convective systems. J. Atmos. Sci., 51, 1089-1099.

$\longrightarrow$, and - 1995: Low-frequency oscillations in radiativeconvective systems. Part II: An idealized model. J. Atmos. Sci., 52, 478-490.

Julian, P. R., and R. A. Madden, 1981: Comments on a paper by T. Yasunari, A quasi stationary appearance of 30 to 40 day period in the cloudiness fluctuation during the summer monsoon over India. J. Meteor. Soc. Japan, 59, 435-437.

Kalnay, E., and Coauthors, 1996: The NCEP/NCAR 40-Year Reanalysis Project. Bull. Amer. Meteor. Soc., 77, 437-471.

Kemball-Cook, S., and B. Wang, 2001: Equatorial waves and air- sea interaction in the boreal summer intraseasonal oscillation. J. Climate, 14, 2923-2942.

Knutson, T. R., K. M. Weickmann, and J. E. Kutzbach, 1986: Global-scale intraseasonal oscillation of outgoing longwave radiation and $250 \mathrm{mb}$ zonal wind during Northern Hemisphere summer. Mon. Wea. Rev., 114, 605-623.

Krishnamurti, T. N., and D. Subrahmanyam, 1982: The 30-50 day mode at $850 \mathrm{mb}$ during MONEX. J. Atmos. Sci., 39, 20882095.

- D. K. Jayakumar, J. Sheng, N. Surgi, and A. Kumar, 1985: Divergent circulation on the 30 to 50 day time scale. J. Atmos. Sci., 42, 364-375.

Lawrence, D. M., and P. J. Webster, 2002: The boreal summer intraseasonal oscillation: Relationship between northward and eastward movement of convection. J. Atmos. Sci., 59, 1593-1606.

Madden, R., and P. R. Julian, 1971: Detection of a 40-50 day oscillation in the zonal wind in the tropical Pacific. J. Atmos. Sci., 28, 702-708.

Ouergli, A., and P. De Felice, 1996: North-eastward propagating 25-50 day mode and its link with Indian summer monsoon activity. Meteor. Atmos. Phys., 61, 127-135.

Sikka, D. R., and S. Gadgil, 1980: On the maximum cloud zone and the ITCZ over Indian longitudes during the southwest monsoon. Mon. Wea. Rev., 108, 1840-1853.

Wang, B., 1988: Dynamics of tropical low-frequency waves: An analysis of the moist Kelvin wave. J. Atmos. Sci., 45, 20512065.

—, and H. Rui, 1990: Synoptic climatology of transient tropical intraseasonal convection anomalies: 1975-1985. Meteor. Atmos. Phys., 44, 43-61.

- and X. Xie, 1997: A model for boreal summer intraseasonal oscillation. J. Atmos. Sci., 54, 72-86.

Webster, P. J., 1983: Mechanisms of monsoon low-frequency variability: Surface hydrological effects. J. Atmos. Sci., 40, 2110 2124.

Yasunari, T., 1979: Cloudiness fluctuations associated with Northern Hemisphere summer monsoon. J. Meteor. Soc. Japan, 57, 227-242.

_ 1980: A quasi-stationary appearance of 30-40 day period in the cloudiness fluctuations during the summer monsoon over India. J. Meteor. Soc. Japan, 58, 225-229.

1981: Structure of an Indian summer monsoon system with a period around 40 days. J. Meteor. Soc. Japan, 59, 336-354. 